\title{
The long and the short of it: gene and environment interactions during early cortical development and consequences for long-term neurological disease
}

\section{Helen Stolp*, Ain Neuhaus, Rohan Sundramoorthi and Zoltán Molnár}

Department of Physiology, Anatomy and Genetics, University of Oxford, Oxford, UK

\section{Edited by:}

Daniela Tropea, Trinity College Dublin, Ireland

Reviewed by:

Francesca Cirulli, Istituto Superiore di Sanità, Italy

Albert Gjedde, University of

Copenhagen, Denmark

Barry Boland, University College

Dublin, Ireland

*Correspondence:

Helen Stolp, Department of

Physiology, Anatomy and Genetics, University of Oxford, Le Gros Clark Building, South Parks Road, Oxford OX1 30X, UK.

e-mail: helen.stolp@dpag.ox.ac.uk
Cortical development is a complex amalgamation of proliferation, migration, differentiation, and circuit formation. These processes follow defined timescales and are controlled by a combination of intrinsic and extrinsic factors. It is currently unclear how robust and flexible these processes are and whether the developing brain has the capacity to recover from disruptions. What is clear is that there are a number of cognitive disorders or conditions that are elicited as a result of disrupted cortical development, although it may take a long time for the full pathophysiology of the conditions to be realized clinically. The critical window for the manifestation of a neurodevelopmental disorder is prolonged, and there is the potential for a complex interplay between genes and environment. While there have been extended investigations into the genetic basis of a number of neurological and mental disorders, limited definitive associations have been discovered. Many environmental factors, including inflammation and stress, have been linked to neurodevelopmental disorders, and it may be that a better understanding of the interplay between genes and environment will speed progress in this field. In particular, the development of the brain needs to be considered in the context of the whole materno-fetal unit as the degree of the metabolic, endocrine, or inflammatory responses, for example, will greatly influence the environment in which the brain develops. This review will emphasize the importance of extending neurodevelopmental studies to the contribution of the placenta, vasculature, cerebrospinal fluid, and to maternal and fetal immune response. These combined investigations are more likely to reveal genetic and environmental factors that influence the different stages of neuronal development and potentially lead to the better understanding of the etiology of neurological and mental disorders such as autism, epilepsy, cerebral palsy, and schizophrenia.

Keywords: neurogenesis, neuronal migration, blood brain barrier, glia, maternal inflammation

\section{INTRODUCTION}

The development of the brain is determined by a complex interplay of intrinsic genetic programs and environmental interactions and in utero depends additionally on numerous materno-fetal interactions. Circulation, oxygenation, metabolic interactions, and immune responses are all orchestrated between the fetus and the mother and largely work in harmony. However, when these interactions malfunction, they could contribute to developmental abnormalities. The unfolding genetic program of cortical development is influenced by these environmental factors in a highly complex fashion. While the developing brain is kept separate from the systemic circulatory system by the brain barriers, and the maternal circulation is separated from the fetal circulation in the placenta, it is clear that changes in the maternal/intrauterine and systemic fetal environments may result in modifications of normal fetal brain development. Therefore, neurological and mental disorders have an array of pathophysiological hallmarks that reflect a complex etiology. These disorders are typically diagnosed by clinical features, as the genetics and molecular basis of the diseases are still largely opaque. There is an emerging field that studies these interactions in the context of barrier biology, immunology, endocrinology, teratology, and developmental neurobiology. The challenge is to relate the genetic and molecular program of neurodevelopment to the various insults (including fetal alcohol and drug exposure, inflammation and hypoxic-ischemia) for the better understanding of the pathophysiological-mechanisms of these developmental disorders. The aim of this review is to discuss the normal cortical developmental program within the context of the developing fetal and maternal environments and give insights to some potential environmental-genetic interactions that contribute to neurodevelopmental disorders. Of particular interest is the possibility that one environmental insult could contribute to multiple diseases, depending on the stage of brain development affected. For example, maternal alcohol consumption or infection can have a specific time window when the consequences are more severe. For the purpose of this review we divide development into four stages. The first three correspond to key periods in neurogenic development: (i) proliferation, (ii) migration, and (iii) initial differentiation. In humans this corresponds to (i) 1-7 weeks, (ii) $8-15$ weeks and, weeks $16-26$, although the true boundaries of 
these processes are not this absolute. We shall also discuss a fourth stage, which in humans is from the 26th week into the postnatal period. This stage largely represents the influence of other cell systems on neuronal functions, such as myelination and activity dependent circuit formation. Boxes $\mathbf{1}$ and $\mathbf{2}$ give summary of the fundamentals of early cortical development for the general reader. The concomitant development of different components of the CNS will be discussed as well as the known pathological consequences of environmental insults during these periods.

\section{MATERNAL/FETAL ENVIRONMENT MATERNAL SIGNALING}

Fetal development is greatly dependent on the maternal environment and it is clear that a spectrum of insults can produce changes in the fetus that include mild fetal growth restriction, through to severe birth defects or still birth. A number of maternal complications have been specifically related to negative fetal outcomes, including pre-eclampsia, depression, diabetes, infection/inflammation, and extremes in body weight (Barker, 2007; Hoerder-Suabedissen et al., 2008; Zammit et al., 2009).

Congenital abnormalities, including cardiovascular and neural tube defects, are more common in offspring of overweight or diabetic mothers, potentially due to the teratogenic effects of hyperglycemia and relaxin (Hawdon, 2011). These maternal conditions can also alter both the systemic and central control of metabolism in the offspring (Meaney et al., 2007; Sirimi and Goulis, 2010; Gluckman et al., 2011; Hawdon, 2011) and may even lead to epigenetic modulation of neural genes regulating

\section{Box 1 | Fundamentals of cerebral cortical development.}

\section{PROLIFERATION}

The telencephalon, which later develops into the cortex and basal ganglia, starts to generate neurons in the mouse from approximately E10.5, with neurogenic divisions occurring from E11-E17 (Rakic and Sidman, 1968). Proliferative cell division occurs first at the ventricular surface (in the ventricular zone, VZ) and then starts basal to this zone, in the subventricular zone (SVZ; Figure 4). As neurogenesis progresses cell division switches from a symmetric, proliferative division to an increasingly neurogenic division (Konno et al., 2008). Once neurogenesis is complete, the same pluripotent progenitors produce glia. During this period there is also vascularization of the telencephalon, invasion of microglia, and migration of GABAergic neurons from the ventral to the dorsal telencephalon (Earle and Mitrofanis, 1997; Parnavelas, 2000; Stubbs et al., 2009).

The different rounds of division in the proliferative zones are responsible for the "birth" of different cortical neuronal populations, which migrate to establish the cortical layers. A combinatorial transcription factor signaling specifies the future phenotype of cerebral cortical neurons (Guillemot et al., 2006; Hevner et al., 2006). The timing of this is largely based on intrinsic genetic programming, as cell populations grown in vitro will differentiate into layer populations after the same number of divisions as observed in vivo (Shen et al., 2006).

\section{MIGRATION}

The cortex develops in an "inside-first-outside-last" fashion, with deep cortical layers born first, and superficial cortical layers born last (Rakic and Sidman, 1968). Cells that are born in the VZ or SVZ proliferative zones migrate into the cortical plate (CP) along the basal projections of the radial glia (Métin et al., 2008). The first cell populations to migrate out of the proliferative zones are the cells of the preplate which are visible as early as E12, and which split to form the marginal zone and the subplate (Marin-Padilla, 1971). Following this, waves of division occur and differentiating neurons migrate past the subplate to form subsequent layers of cortical pyramidal projection neurons (Bystron et al., 2008). The contribution of the VZ and SVZ to the cortical layers is a subject of contention. In general it is thought that VZ progenitors contribute neurons to the lower cortical layers (V and VI) and to the SVZ, while the SVZ is the primary source of upper cortical layers (IV and II/III; Tarabykin et al., 2001; Wu et al., 2005), but there is evidence for SVZ neurogenesis for all layers (Kowalczyk et al., 2009).

There is a degree of plasticity in the genetically programmed cell fate, where extrinsic signaling factors such as neurotrophins (including nerve growth factor, brain-derived neurotrophic factor, neurotropin-3, and neurotrophin-4) can alter the differentiation of late generated neurons (Fukumitsu et al., 2006). The degree of plasticity appears to decrease, and may be restricted (Desai and McConnell, 2000). There are a number of examples where late born neurons may take on protein expression of early cortical layer subtypes, but still migrate to their later cortical layer (Fukumitsu et al., 2006).

\section{DIFFERENTIATION}

Recent studies have elucidated a large number of molecules that are associated with specific cortical layers (Guillemot et al., 2006; Molyneaux et al., 2007; Belgard et al., 2011), in some cases these genes (e.g., Satb2, Ctip2, Fezf2) appear to be involved in fate specification of neuronal precursors, and are expressed in the proliferative zones at the time of layer birth and then continue in the differentiated neuronal population (Alcamo et al., 2008; Britanova et al., 2008; Chen et al., 2008).

Full maturation of the cortex requires cellular differentiation, target connection, and strengthening. The majority of this process occurs in the late embryonic and postnatal period in rodents. In humans it can continue into adolescence. The glutamatergic CP neurons will integrate with the GABAergic interneurons into functional circuits (Fishell and Rudy, 2011).

The early steps of cerebral cortical circuit formation are orchestrated by subplate (Kostovic and Rakic, 1990). In mouse, subplate neurons are a largely transient population of neurons that sit at the base of the CP, in layer VIb in the postnatal brain (Hoerder-Suabedissen et al., 2009). The subplate forms the earliest cortical projections and appears to act as a scaffold for the establishment of connections with subcortical structures, e.g., the thalamus (Allendoerfer and Shatz, 1994; Molnár and Blakemore, 1995). It has recently been hypothesized that these cells have different roles in the brain depending on the developmental stage, and that earlier in telencephalic development the subplate is key in guiding thalamic projections, while at later stages the remaining subplate cells may integrate more into cortical networks to orchestrate the development of the ultimate cortical circuits (Kanold and Luhmann, 2010). 


\section{Box 2 | Progenitors of the developing cortex.}

As the telencephalic vesicles expand from the neural tube the ventricular surface is composed of neuroepithelial progenitors. These cells undergo symmetric proliferative divisions to increase the pool of progenitor cells (Breunig et al., 2011). They are considered to be neural progenitor cells, as their daughter cells are able to produce a number of different cell types (reviewed in Pinto and Götz, 2007). However, unlike other stem cell populations, the neuroepithelial cells are heterogeneous and appear to be restricted both in number of potential divisions and the fate of daughter cells (Williams and Price, 1995; Gal et al., 2006; Lui et al., 2011). As the cortex develops, the proliferative population in the ventricular zone undergoes changes. These changes include a slight loss of the apical-basal polarity that is so characteristic of the neuroepithelial cells, and are considered to be required for the switch from proliferative to neurogenic divisions (Aaku-Saraste et al., 1996; Lui et al., 2011).

A number of factors combine over a very short period of development to allow division to switch from symmetric, proliferative division to asymmetric, neurogenic division (where one progenitor and one neuron are produced from a mitotic event; Sahara and O'Leary, 2009). The division of the cell contents, and most particularly the apical polarity and adherence components, appears to be responsible for whether division will be symmetric or asymmetric (Farkas and Huttner, 2008). Current evidence suggests that even distribution of the cell contents, characterized by vertical mitotic division in the early developing cortex, is associated with symmetric, proliferative division. In comparison, uneven distribution, visible by an angled or horizontal mitotic cleavage, is associated with asymmetric, neurogenic divisions (Zhong and Chia, 2008; Fietz and Huttner, 2011).

Another factor that appears important for the switch from proliferative to neurogenic division is the length of the cell cycle. There is clear evidence that radial glial progenitors undergoing neurogenic division have a longer G1 phase than neuroepithelial cells undergoing symmetric, proliferative divisions, and that experimentally lengthening the $\mathrm{G} 1$ phase in neuroepithelial progenitors will induce neurogenesis (Hartfuss et al., 2001; Lukaszewicz et al., 2002; Calegari et al., 2005; Wilson et al., 2011).

Once neurogenesis has started in the VZ, basal progenitor cells can also be observed in the SVZ. Basal progenitors have lost their apical projections and undergo division at the basal margin of the VZ. They typically undergo symmetric, neurogenic proliferation and are regulated by a different set of transcription factors, including Tbr2 (Noctor et al., 2004; Hevner et al., 2006).

behavior (Keverne, 2010). Maternal psychosocial stress has been found to result in altered fetal weight, insulin resistance, metabolic, immune and endocrine function, and decreased cognitive performance (Entringer et al., 2010) which is likely to be mediated through glucocorticoid exposure and regulation (Meaney et al., 2007; Harris and Seckl, 2011). Hypoxia, while a normal part of placental vascularization, can become pathological in pre-eclampsia (Redman and Sargent, 2005) or inflammatory conditions such as malarial infection (Rogerson and Boeuf, 2007). Chronic intrauterine hypoxia will result in reduced fetal growth and ischemic brain damage (Redman and Sargent, 2005; Duncan et al., 2006; Rogerson and Boeuf, 2007; Gunn and Bennet, 2009). Cytokines are also a normal part of the regulatory system during pregnancy (Orsi and Tribe, 2008), and like hypoxia, dysregulation of the cytokine response locally or systemically has been associated with poor fetal outcome (Orsi and Tribe, 2008). Chorioamnionitis is a wellcharacterized maternal inflammatory condition, which increases circulating cytokines and has been associated with developmental brain damage (Impey et al., 2001). There is clear evidence that changes in fetal, rather than maternal, inflammation correlates more reliably with severity of neurological outcome (e.g., Yoon et al., 2000). The contribution of the fetal environment to neurological damage will be discussed below.

\section{ROLE OF THE PLACENTA}

Placental tissue is of trophoblast origin, but has maternal and fetal compartments, based on the domains of circulating blood. The umbilical arteries, veins, and the fetal capillaries make up the fetal circulation, while the maternal blood enters the intervillous spaces from the spiral arteries and exit via the uterine veins (Schoenwolf and Larsen, 2009). The cells that border the intervillous space, including syncytiotrophoblasts and cytotrophoblasts, provide a barrier between the maternal and fetal circulation (Figure 1) that change during pregnancy to meet the increased demand of the growing fetus (Neerhof and Thaete, 2008). The placenta contributes to many aspects of normal fetal development and early life programming (Murphy et al., 2006), and has been shown to contribute directly to early brain development by providing morphogenic serotonin (Bonnin et al., 2011). Monoamine neurotransmitters start to accumulate within the cortex from E17.5 through to P30 in the mouse (Cheng et al., 2010), 5-HT in particular at the earliest stages of this period. Knockout $(\mathrm{KO})$ of the monoamine oxidases has been shown to modulate proliferation in the intermediate progenitor cells within the cortex at E17.5 and in the progenitor cells within the SVZ at P2 and in the adult (Cheng et al., 2010). Studies of Bonnin et al. (2011) suggest a new, direct role for placental metabolic pathways in modulating fetal brain development. Understanding such maternal-placental-fetal interactions and 5-HT may hold the key to the understanding of the etiology of some adult mental disorders.

Placental insufficiency has generally been retrospectively diagnosed following evidence of intrauterine growth restriction (IUGR; Huppertz et al., 2006), and may partly explain the high association between IUGR and brain dysfunction (Rees et al., 2008; Raikkonen and Pesonen, 2009). Maternal inflammation, which has also been clearly linked to brain damage in the developing offspring, has been found to cause reduced placental blood flow and may cause damage through a hypoxic as well as inflammatory pathway (Girard et al., 2010). However, low-level continuous inflammation in the fetus can cause brain damage without hypoxia (Duncan et al., 2006). It is generally considered that the placenta provides a barrier that prevents direct infection of the fetus (Ashdown et al., 2006; Hutton et al., 2008). However, Dahlgren et al. (2006) and Hsiao and Patterson (2011) have shown that maternally produced IL- 6 can be found in the fetal circulation and correlates with long-term behavioral deficits in the offspring, suggesting that 


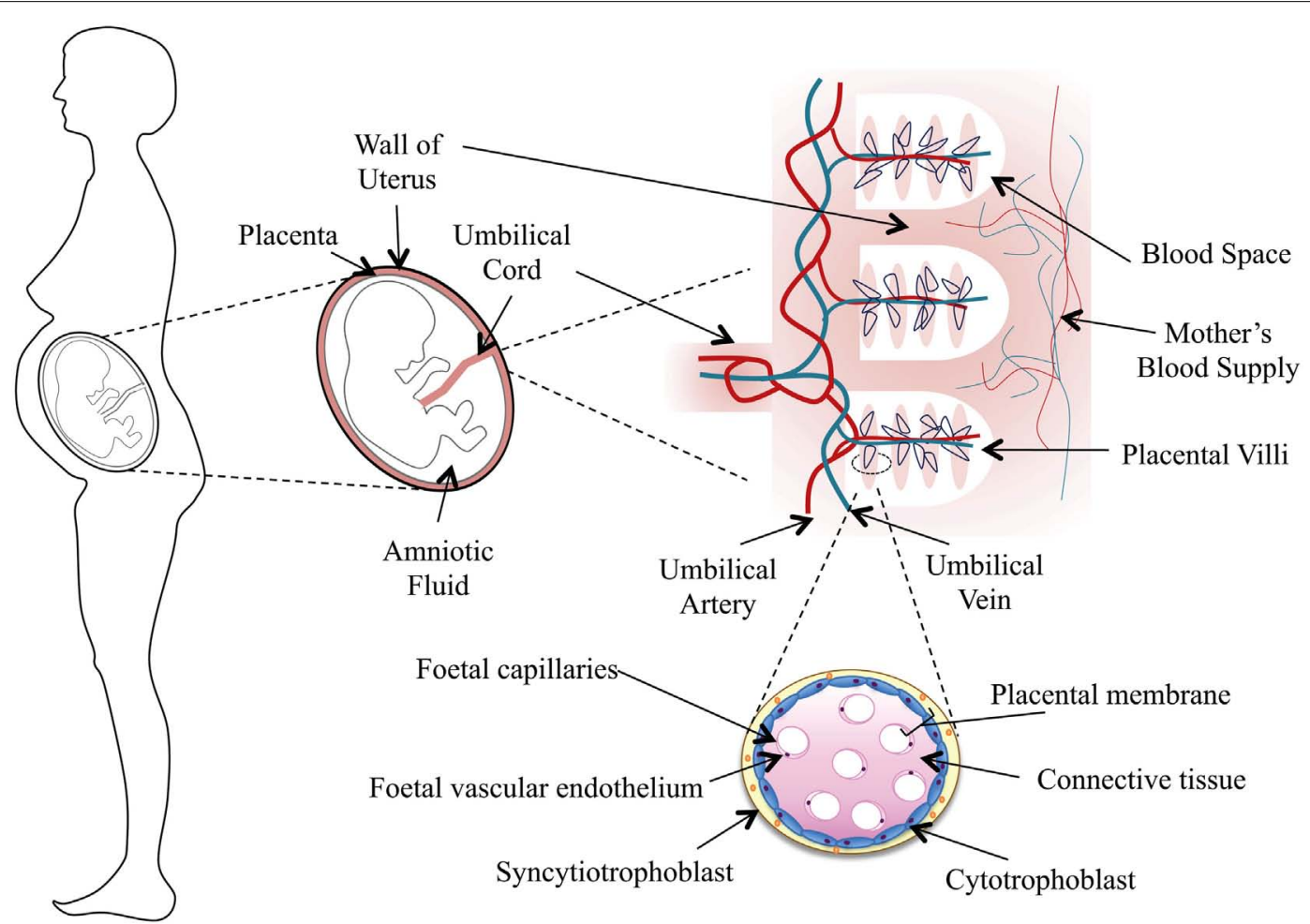

FIGURE 1 | Schematic illustration of the fetal environment and placental structure. The fetus develops in the uterus isolated from the maternal circulation through the materno-fetal barrier in the placenta. The maternal blood enters the intervillous spaces from the spiral arteries. There is transfer from the intervillous space across the placental barrier to the fetal capillary network that joins the umbilical vessels. The syncytiotrophoblasts, cytotrophoblasts, and connective tissue that make up the placental membrane are the key structures of the placental barrier. inflammation is still able to pass from the mother to the fetus despite this barrier.

\section{FETAL IMMUNE RESPONSE}

There is extensive epidemiological and experimental evidence suggesting that the presence of inflammatory mediators in the fetal circulation, particularly those produced by the fetus, are the best predictors of fetal brain damage (Yoon et al., 2000; Badawi et al., 2006; Elovitz et al., 2011). The maturity of the fetal immune response may therefore contribute to the outcome of maternal/intrauterine insults. Circulating inflammatory cells, including T-cells, B-cell, and macrophages, are produced as early as 7 weeks in humans (approximately E10 in mice; Melchers, 1979; Solvason and Kearney, 1992; Holt and Jones, 2000). However, T-cell precursors, in particular, are functionally immature at this stage, which may contribute to abnormally strong innate immune responses to inflection (Haynes et al., 1988; Michaelsson et al., 2006; Zhao et al., 2008). Antigen presentation is also impaired during development, as major histocompatibility complex (MHC) class II expression is reduced on antigen presenting cells (Jones et al., 2002) although some accessory proteins may be expressed at adult levels.

The liver bud is responsible for the production of acute phase proteins, which occurs from E16 onward in the rat liver in response to pro-inflammatory cytokines such as IL-6 (Thomas et al., 1990), and some acute phase proteins (e.g., $\alpha_{2}$-macroglobulin) are known to be expressed already at E12 in the rat liver (Fletcher et al., 1988). C-reactive protein (CRP) in humans is expressed, and developmentally regulated, in preterm neonates with or without placental inflammation (Leviton et al., 2011). CRP levels are specifically associated with the severity of cortical growth retardation in preterm children (Kaukola et al., 2009); other acute phase proteins are associated with white matter damage (Leviton et al., 2011), but the evidence for direct pathological effects of acute phase proteins in cortical development is scarce. However, peptides homologous to CRP and other acute phase proteins are known to play a role in synaptic refinement in the developing cortex (Bjartmar et al., 2006).

\section{ENDOCRINE INTERACTIONS BETWEEN FETUS AND MOTHER}

CNS glucocorticoid receptors and thyroid hormone receptors are expressed from very early in development (Kitraki et al., 1996, 1997); although their level of expression is considerably less than in adults. Cortical effects of both under- and overexposure to glucocorticoids have been described in animal models, including changes in CP size and maturity in a model of maternal adrenalectomy on day 1 of pregnancy (Trejo et al., 1995), and stress during pre- and postnatal life is associated with a wide variety of neurological disorders (Cirulli et al., 2009; Harris and Seckl, 2011). Glucocorticoids are intertwined with immune system function as well, inhibiting inflammatory responses and cytokine expression. Antenatal steroid use has been associated with reduced mortality 
and complications in preterm children (Whitelaw and Thoresen, 2000). However, multiple courses of steroids have also been associated with reduced brain growth, impaired myelination, and other abnormalities (Whitelaw and Thoresen, 2000). There is substantial epidemiological evidence to implicate hypothyroidism in developmental cognitive/behavioral deficits (Zoeller and Rovet, 2004; Berbel et al., 2009) including impaired visuomotor skills, low IQ, ADHD, cerebellar dysfunction, and hearing impairment (Ahmed et al., 2008; Berbel et al., 2009; Patel et al., 2011). Estrogens have also been implicated in embryonic neurogenesis, (Brinton, 2009), with an E2 synthesizing enzyme found in the embryonic cortex and the estrogen receptor-alpha is present on progenitor cells during cortical neurogenesis (Martínez-Cerdeño et al., 2006). Furthermore, E2 administration rapidly promotes proliferation, and in utero blockade of estrogen receptors decreases proliferation of embryonic cortical progenitor cells (Martínez-Cerdeño et al., 2006).

\section{VASCULAR DEVELOPMENT AND THE BRAIN BARRIERS}

The cardiovascular system is the first to become functional in the embryo (Brand, 2003). Due to its high metabolic demands, the cortex receives profuse blood supply, which initiates as two plexi, which progressively become less discrete and vascular density is much more uniform in late gestation (Virgintino et al., 1998; Javaherian and Kriegstein, 2009; Stubbs et al., 2009; Liebner et al., 2011; Figure 2).

Angiogenesis is controlled by numerous soluble ligands and their receptors, with some ligands (notably VEGF) playing different roles depending on the stage of vessel development (for extensive reviews see Hanahan, 1997; Gaengel et al., 2009; Quaegebeur et al., 2010). Pericytes are recruited to the vessels via endothelial platelet-derived growth factor (PDGF). The loss of pericytes leads to abnormal capillary morphology and microaneurysms (Lindahl et al., 1997). The developing vasculature is closely associated with early neurogenic compartments in the telencephalon (Javaherian

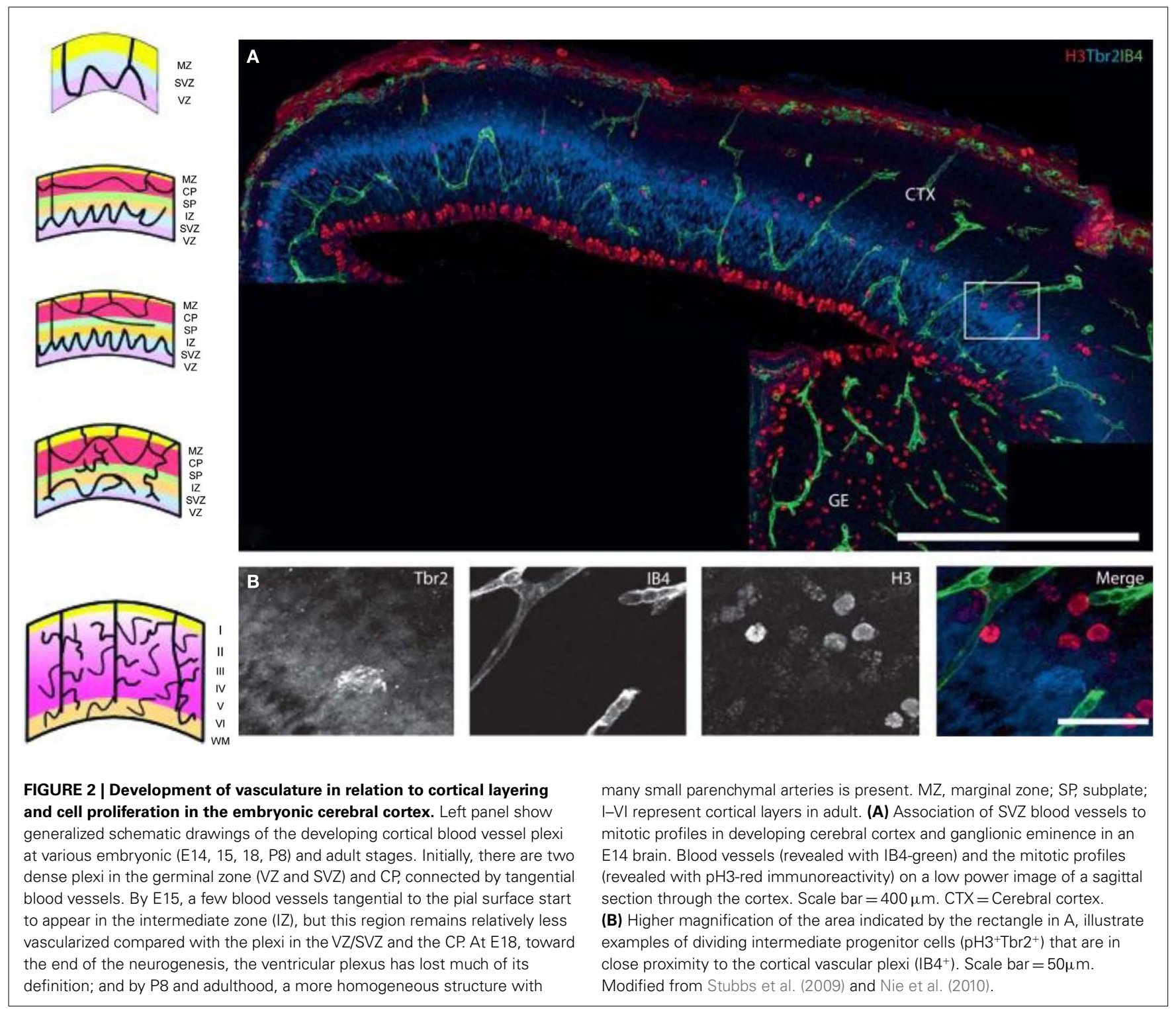


and Kriegstein, 2009; Stubbs et al., 2009; Nie et al., 2010; Figure 2), and many signaling molecules are shared between these developing systems (discussed below).

The CNS vasculature features the added complexity of the blood-brain barrier (BBB) (Figure 3A), which is required for ionic and neurotransmitter homeostasis, protection from neurotoxic agents, and selective provision of nutrients (Neuwelt et al., 2011). The BBB involves both tight junction formation (the failure of which critically impairs BBB function; Nitta et al., 2003), as well as reduced vesicular transport and a specific asymmetric polarity of endothelial transporter expression, e.g., GLUT-1 (Dobrogowska and Vorbrodt, 1999). There is evidence that the first penetrating intraneural capillary (at E10) showed no fenestrations and junctional complexes between endothelial cells (Bauer et al., 1992) and are impermeable to even very small molecules (Ek et al., 2006). The brain is also separated from the external environment by the arachnoid barrier on the surface of the brain and the epithelial barrier at the choroid plexus (Figure 3C), which are also present early in development (Ek et al., 2001, 2003, 2010; Johansson et al., 2005) suggesting a functional barrier and protective system. The composition of the cerebrospinal fluid (CSF) is different in the developing brain compared to the adult (Dziegielewska et al., 1981), which appears to be due to a developmentally regulated specific transfer mechanism across the choroid plexus epithelial cells (Habgood et al., 1992; Liddelow et al., 2009, 2011) that is important for normal brain development (Johansson et al., 2008, discussed in more detail below).

Disruption of the BBB has been identified in an age-specific manner following both systemic and centrally induced inflammation. Interestingly, the window of susceptibility appears to be different for these, depending on the site of inflammatory stimuli. Systemic inflammation caused by LPS injection produces

\section{Blood-brain barrier}

A (Cerebral blood vessels)

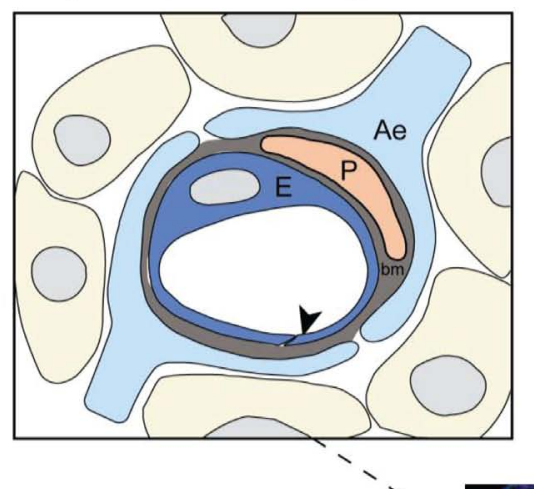

B

\author{
Blood-CSF barrier \\ (Choroid plexus)
}

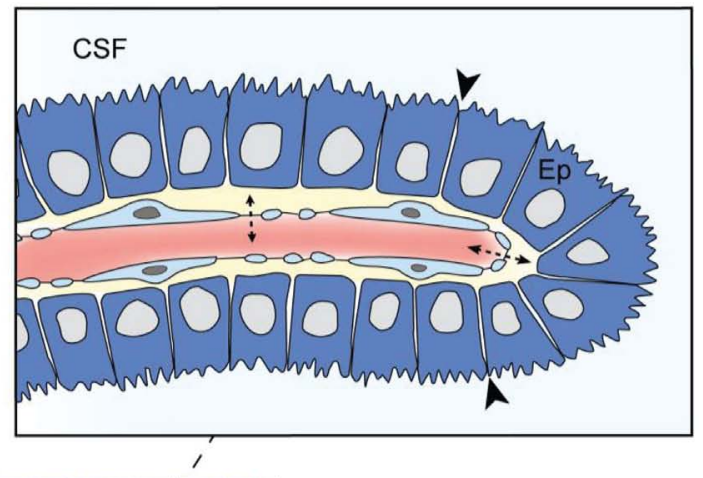

C Meningeal barrier

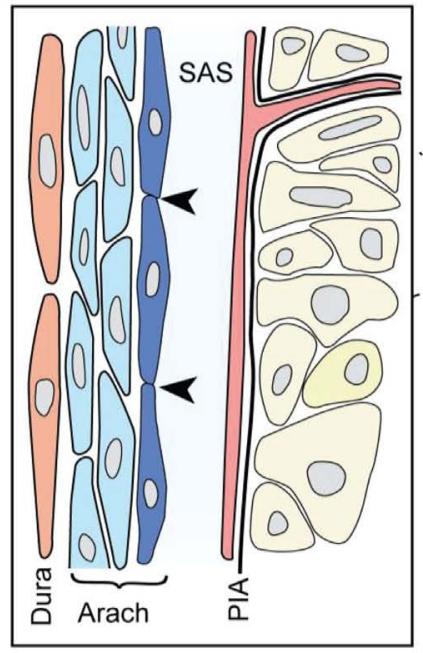

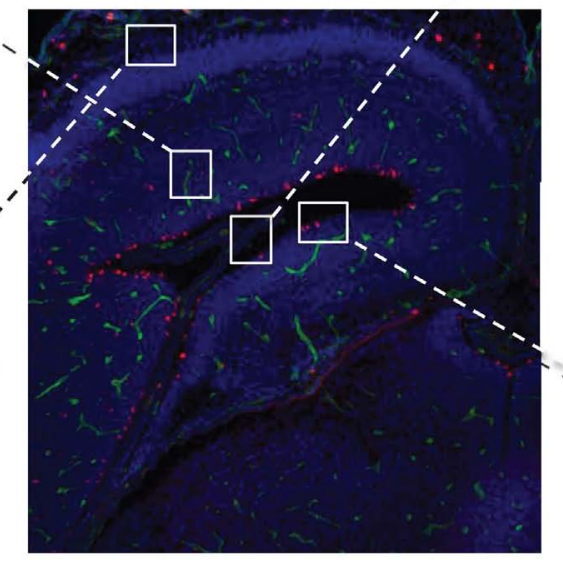

D Fetal CSF-brain barrier (Neuroependyma)

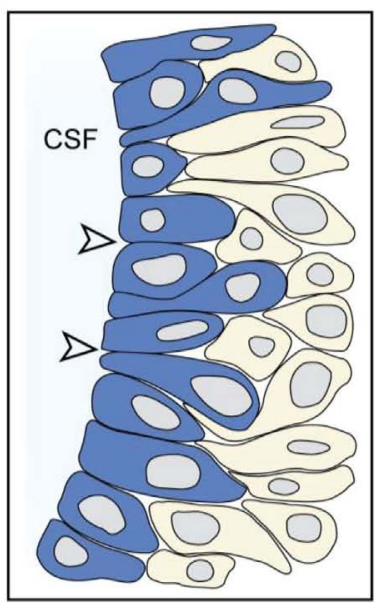

FIGURE 3 | Schematics of the brain barriers. Barrier interfaces in the brain are indicated in blue in the schematic diagrams of the blood-brain barrier, blood-CSF barrier, meningeal barrier, and fetal CSF-brain barrier. The primary site of the blood-brain barrier $(\mathbf{A})$ is the endothelial cells of the cerebral blood vessels (E), supported by pericytes (P) and astrocytic endfeet (Ae). In the choroid plexus (B) the epithelial cells (Ep) are the barrier interface of the
blood-CSF barrier, as the endothelial cells in the stroma are fenestrated. The meningeal barrier (C) is at the boarder of the arachnoid membrane (Arach) and the subarachnoid space (SAS). The fetal CSF-brain barrier (D) exists during early development, at the endfeet of the radial glial progenitors. This forms a barrier between the CSF and the developing parenchyma. Modified from Saunders et al. (2008). 
disruption of the $\mathrm{BBB}$ in white matter tracts in the first postnatal week in rats (Stolp et al., 2005), whereas IL-1 $\beta$ in the striatum produces a substantial increase in barrier permeability in juvenile animals, but not neonates or adults (Anthony et al., 1997). Previous work (Stolp et al., 2005) suggests that the blood-CSF barrier (Figure 3B) does not have an altered permeability following systemic inflammation, however it has been hypothesized that the function of the choroid plexus epithelial cells may change, altering the composition of the CSF (discussed below).

\section{TELENCEPHALIC ENVIRONIMENT DURING PROLIFERATION, MIGRATION, AND DIFFERENTIATION}

The environment surrounding the developing brain is, therefore, complicated and the different developmental timetables for organs and regulatory systems can interact to cause variation in brain development. The environment within the developing brain can be described in a similar manner. Many different cell types are produced within the brain and need to differentiate, migrate, and integrate effectively to produce normal brain function.

\section{VASCULAR REGULATION AND NEUROGENIC NICHE}

The developmental control of the vasculature goes hand-in-hand with neurogenesis in the brain. There is clear evidence that angiogenesis follows morphogenic factors such as Dlx1/2, Nkx2.1, and Pax6 to produce a ventricular vascular plexus that develops in a ventral-dorsal gradient (Vasudevan et al., 2008). This plexus extends in the dorsal telencephalon as the SVZ is established (Vasudevan et al., 2008), and it appears that progenitors within the SVZ exist within a neurogenic vascular niche (Javaherian and Kriegstein, 2009; Stubbs et al., 2009; Nie et al., 2010) that has also been well established in the adult brain (Shen et al., 2008). There are many similarities and interconnections between cardiovascular and cortical development. For instance, the outgrowth and alignment of blood vessels relies on molecular signals such as semaphorins and netrins, cues also used within the developing nervous system (reviewed by Larrivee et al., 2009). One clear example is VEGF, which is known to be crucial in vascular development (Carmeliet et al., 1996) but some isoforms also regulate proliferation in the neuroepithelium (Darland et al., 2011).

\section{CEREBROSPINAL FLUID}

The CSF in the developing brain plays an important role in cerebral expansion (Gato and Desmond, 2009). CSF is secreted by the choroid plexus, which develop from as early as E12 in the rat (Dziegielewska et al., 2001). The primary role of the choroid plexus is to secrete and control the composition the CSF and the cellular mechanisms for CSF secretion, such as aquaporin expression, are established from the day of choroid plexus appearance (Johansson et al., 2005). The choroid plexus regulates the protein composition in the CSF by either production (e.g., TTR, Igf2; Dickson et al., 1986; Hynes et al., 1988; Southwell et al., 1993) or specific transfer from the blood (Habgood et al., 1992; Johansson et al., 2006; Liddelow et al., 2009), which result in their high concentration within the CSF during early development (Dziegielewska et al., 2001; Johansson et al., 2008). It has been well established that the high protein content of developmental CSF is important for cortical expansion (Gato and Desmond, 2009), but initial experiments only assessed this in terms of providing an osmotic force for ventricular, and therefore cortical, expansion. However, recent experiments have confirmed that proteins within the CSF interact with receptors on the ventricular surface and regulate proliferation within the VZ (Martin et al., 2006; Lehtinen et al., 2011). The generally high CSF protein concentration decreases in the rat at approximately E17 (Johansson et al., 2008), but it is likely that specific proteins within in the CSF still occur at high concentrations during the embryonic period and continue to influence neurogenesis (e.g., Igf2; Lehtinen et al., 2011).

\section{MICROGLIA}

Linage tracing has been used to demonstrate that microglia are derived from the systemic progenitors and migrate into the brain around E9.5 in the rodent (Ginhoux et al., 2010). Microglia slowly increase in number within the brain, with higher distribution density within the meninges and the VZ/SVZ border followed by increasing density in the $\mathrm{CP}$ as gestation continues (Antony et al., 2011). Microglia are considered to play a role during these early stages of development in supporting the proliferation of progenitors within the cortex. While depletion of microglia from the developing brain in PU.1 ${ }^{-1-}$ mice (McKercher et al., 1996) is associated with grossly normal cortical development up to E16 (when animals die due to hematopoietic dysfunction) there is some evidence that there is decreased cortical proliferation in the absence of microglia, which ultimately leads to a reduction in astrocyte numbers (Antony et al., 2011). At an equivalent stage of development, altered microglia function, by a loss-of-function mutation in the DAP12 gene, also provides evidence that microglia affect neuronal maturation and later synaptic formation and function (Roumier et al., 2008).

In the fourth phase of telencephalic development there is a massive increase in the number of microglia (up to 20-fold) that can be specifically observed with an amoeboid phenotype within white matter tracts (Prinz and Mildner, 2011). Microglia slowly spread through the entire CNS throughout the postnatal period and take on a "resting," ramified phenotype (Hristova et al., 2010). During this period, when microglia have previously been considered to be static, there is evidence that they play a role in synaptic pruning and may be important for aspects of structural reorganization associated with LTP and LTD (Schlegelmilch et al., 2011). Recently, microglia have been shown to engulf and eliminate synapses during development (Paolicelli et al., 2011). Microglia activation is considered a natural step in elimination of juvenile connections, e.g., in the corpus callosum or during normal formation of the barrel cortex (Berbel and Innocenti, 1988; Maki Hoshiko, Nobuhiko Yamamoto and Etienne Audinat et al., unpublished), and has been demonstrated in pathological neural activity (Avignone et al., 2008) both are highly suggestive of functional involvement in cortical circuit remodeling. There is evidence that the chemokine fractalkine (CX3CR1) is important in mediating microglial synaptic pruning. In $\mathrm{KO}$ mice unable to produce the fractalkine receptor $(\mathrm{Cx} 3 \mathrm{cr} 1 \mathrm{KO})$ there is a decrease in microglial densities in developing brain regions and newborns had an excess of dendritic spines and immature synapses, although these changes were found to be transient (Paolicelli et al., 2011). Interestingly, mice lacking functional Hoxb8 (a transcription factor that is involved in the development of the hematopoietic system) exhibit 
obsessive grooming behavior, which is linked to the loss of the Hoxb8 microglial population in the brain (Chen et al., 2010). This provides a novel link between microglia and behavioral evidence of neuropathology.

\section{ASTROGLIAL DEVELOPMENT}

During stage 3 of telencephalic development, there is a switch from neurogenesis to gliogenesis (Figure 4). Experiments using fluorescence-activated cell sorting and time-lapse microscopy show radial glia can generate astrocytes as well as neurons (Malatesta et al., 2000; Noctor et al., 2004; Box 2). The neuron to glia switch is reliant on both cell-intrinsic and extracellular cues. Early in forebrain development the promoters of GFAP and S100B are methylated, ensuring astrocyte development is repressed (Juliandi et al., 2010). Demethylation increases the sensitivity to extracellular cues such as developmental cytokines (Molne et al., 2000; Juliandi et al., 2010). Neurons are known to secrete cytokines involved in gliogenesis, particularly members of the IL- 6 family: LIF, CNTF, CT1 (Juliandi et al., 2010). Embryonic cortical neurons can regulate the onset of cortical gliogenesis via cardiothrophin-1 (Barnabe-Heider et al., 2005). This is a neural feedback mechanism whereby newly born neurons can instruct precursors to generate astrocytes via the secretion of cytokines, ensuring that gliogenesis does not occur until after neurogenesis. The use of cytokines in regulating the development of glia leaves the possibility that gliogenesis can be disrupted by additional cytokine production following an environmental insult such as perinatal inflammation.

Following astrocyte specification, precursors migrate to their final positions where they begin the process of terminal differentiation. Astrocytes initially migrate tangentially along white matter tracts and then move in a radial direction in the gray matter (Jacobsen and Miller, 2003). The major waves of rodent CNS synaptogenesis occur during the first 2-3 weeks of postnatal life and astrocytes are known to secrete molecules that induce synapse formation (Christopherson et al., 2005; Kucukdereli et al., 2011). Their influence on synaptic function might be stage-specific and modulate well described periods of developmental plasticity. The early experiments by Müller and Best (1989) demonstrated that the transplantation of astrocytes from the visual cortex of newborn kittens into the visual cortex of adult cats reinstalls ocular-dominance plasticity in adult animals.

\section{OLIGODENDROCYTES}

Oligodendrocyte precursors are produced from three different waves of division, from different progenitor populations, primarily in the third and fourth phases of telencephalic development. The majority of oligodendrocyte precursors originate from the

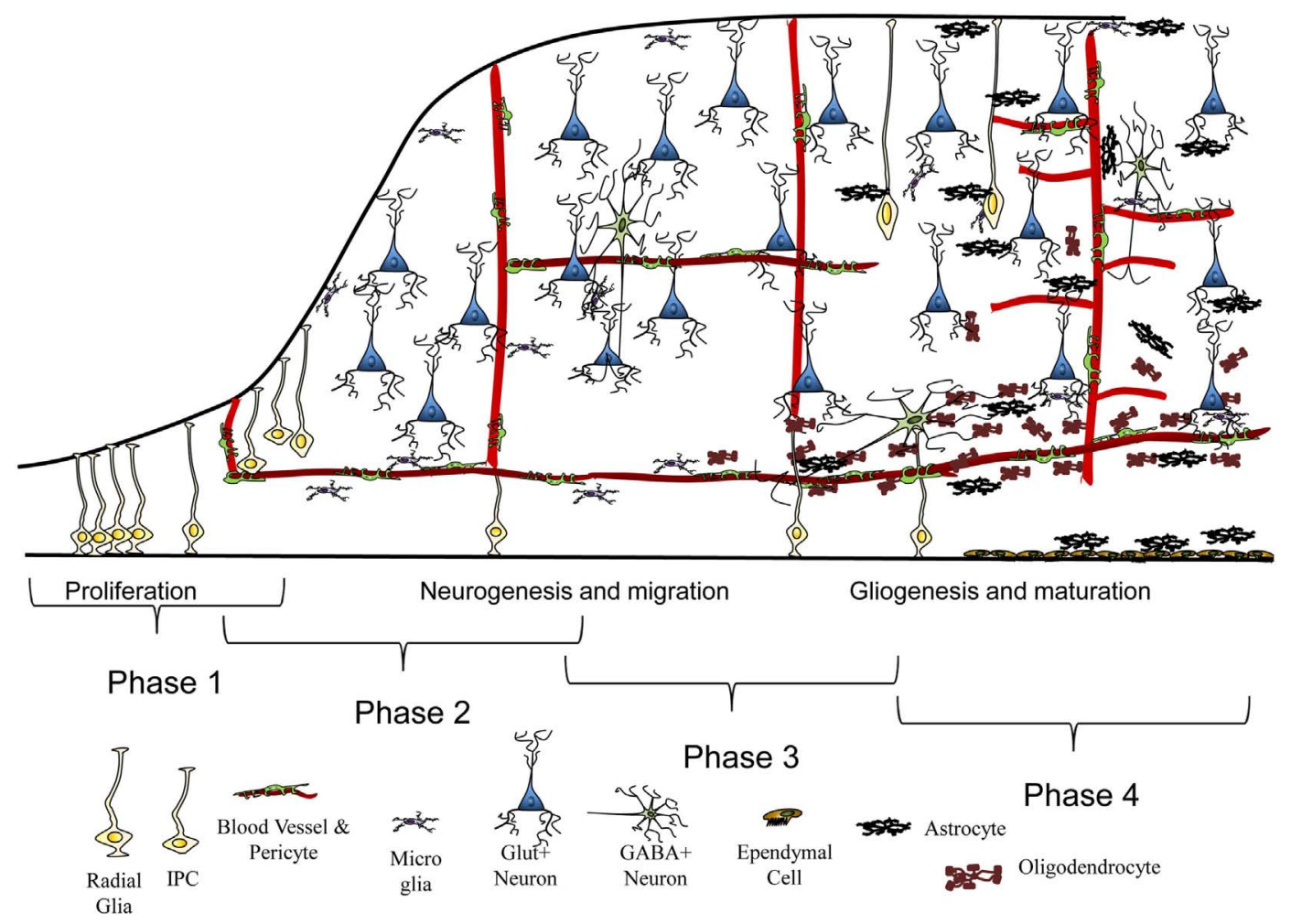

FIGURE 4 | Pattern of telencephalic development. Schematic indicating the increasing complexity of the brain over time. Initially proliferation occurs to increase the size of the progenitor pool (phase 1 of telencephalon development). As neurogenesis starts, vascular plexi, supported by pericytes, form and microglia infiltrate the brain. A second proliferative zone in the SVZ forms. Neurons migrate and differentiate into cortical layers in an inside out manner during phase 2 and 3 of development. In phase 4 of development, gliogenesis occurs in the dorsal and ventral telencephalon. GABAergic interneurons increase their migration into the cortex. There is vascular remodeling and a maturation and integration of connections between neurons, supported by the micro and macroglia. 
ventricular zones in the ganglionic eminences of the ventral telencephalon, a brain region that is also responsible for the production of interneurons (see below). Two prenatal waves of production occur from this zone in the rodent, with the oligodendrocyte precursors migrating to the cortex before full maturation and myelination occurs. A third, postnatal, wave of production occurs in the dorsal ventricular zone after the completion of neurogenesis (Kessaris et al., 2006). In both proliferative zones oligodendrocyte precursors are produced as part of a fate restriction of the neural stem cells that occurs by a largely epigenetic regulation (Liu and Casaccia, 2010). The cross-talk that occurs between transcription factors, which is regulated by DNA methylation or acetylation, provides an initial support for astroglial genesis, that switches to support oligodendrogenesis over the developmental period (Liu and Casaccia, 2010; Rivera et al., 2010). In both the ventral and dorsal telencephalon, Wnt signaling has been implicated in activating oligodendrogenesis over the previous astroglial or interneuron proliferative fates (Langseth et al., 2010; Zhong et al., 2011).

\section{INTERNEURONS}

Approximately $25 \%$ of cortical neurons are inhibitory GABAergic interneurons, which arise from precursors in the subpallium and tangentially migrate into the developing neocortex (Wonders and Anderson, 2006). The rodent interneurons arise mainly from the ganglionic eminences (Lavdas et al., 1999; Wichterle et al., 1999; Anderson et al., 2001; Jimenez et al., 2002; Nery et al., 2002), from approximately E12.5 until birth (Flames and Marín, 2005). There is considerable evidence that rodent models do not accurately reflect the complexity of the primate cortex, which likely receives interneurons from the ventricular zone, SVZ and subpial granular layer in addition to the GE (Letinic and Rakic, 2001; Letinic et al., 2002; Wonders and Anderson, 2006; Jones, 2009; Petanjek et al., 2009). However, this issue in human is not yet resolved (Clowry et al., 2010; Hansen et al., 2010). The establishment of interneuron networks in rodents begins a few days before the glutamatergic network and continues until postnatal life (Cossart, 2011). The origin of interneurons, both in terms of their birth date and region of origin, contributes to determining their electrophysiological properties and neurochemical characteristics (Butt et al., 2005). Birth date and phenotype also predict the laminar fate of interneurons in the rat (Rymar and Sadikot, 2007). Interneuron migration is thought to be induced by motogenic factors such as neurotrophins and hepatocyte growth factor; the pattern of interneuron migration is established by a variety of chemoattractive and chemorepulsive cues, including stromal-derived factor 1 , neuregulins, slit proteins, and ephrins (Hernandez-Miranda et al., 2010). The correct integration of interneurons during CNS development is essential for normal coordinated brain function. Epilepsy and schizophrenia are two neurodevelopmental conditions that occur, at least in part, as a result of interneuron dysfunction (discussed below).

\section{CAUSES OF TELENCEPHALIC INJURY}

It is clear that many elements contribute to a fully functional central nervous system, and that dysfunction in one can have widespread consequences, however establishing etiology of neurodevelopmental disorders has been difficult (see Box 3). Genes that have been associated with these conditions typically have low penetrance and may confer risk for a number of distinct clinical conditions. Likewise, a wide number of environmental insults, such as inflammation and hypoxia, have been indicated by epidemiological studies to contribute a small but significant risk to many neurological and mental disorders. Gene-environment interactions or other forms of confounding insults, along with the developmental windows of susceptibility are now a focus of current research aiming to explain these observations.

\section{TWO-HIT HYPOTHESIS AND WINDOW OF VULNERABILITY}

A "two-hit" hypothesis has been put forward in a number of diseases where onset of disease cannot clearly be linked to a specific genetic or environmental insult. In diseases such as schizophrenia and autism, there is evidence for both genetic contributions and environmental insults, but neither one accurately predicts disease. Support for a two, or multiple, hit etiology for these diseases is particularly strong as limited clear neuropathology has been identified that can be linked to one specific genetic or environmental insult. Instead, a wide variety of broadly linked functional systems are effected, including genes involved in synapse formation, cellcell signaling, and trophic pathways, and injury widely affecting GABA, dopaminergic, and glutamatergic transmission (Maynard et al., 2001). It has been hypothesized that the first hit in schizophrenia may affect neurogenic and cell specification pathways, such as Notch, while the second hit may have a greater effect on functional integration (Maynard et al., 2001).

The term two-hit hypothesis has also been used to describe the increased deficit caused by two or more low-level cytotoxic insults, which combine to produce greater long-term damage. In a basic, proof of principal study, Genetta et al. (2007) have shown an additive cytotoxic effect of low dose alcohol and hypoxia exposure in primary neuron cultures. There have also been many studies showing that inflammation combined with hypoxia can cause increased neurological injury. Inflammation induced by lipopolysaccharide injection 4,6 , or $72 \mathrm{~h}$ prior to hypoxic-ischemic injury has been found to significantly increase infarct size in postnatal day 7 rats (Eklind et al., 2001, 2005). Prenatal LPS exposure has also been associated with increased sensitivity to later hypoxic insult in the immature brain (Larouche et al., 2005). However, the mechanism of this sensitivity is confused, and may be due to the priming of the immune cells (Williamson et al., 2011; Bilbo et al., 2012). In comparison, inflammation as a first hit in schizophrenia is presumed to cause long-term changes in brain structure or function that occur at a subclinical level and are exposed by a second hit in later life (Meyer et al., 2005, 2006; Fatemi et al., 2008; Meyer and Feldon, 2009). Interestingly, there is also some evidence that insults during early life may contribute to neurodegenerative disease later in life. For example, inflammation during embryology (E10.5 in the mouse) results in loss of dopaminergic neurons in the basal ganglia, and increased sensitivity to the 6-hydroxydopamine neurotoxin later in life (Ling et al., 2002, 2004). This substantial decrease in dopaminergic neurons may also increase the susceptibility of affected individuals to "normal" age-induced cell loss, and may account for cases of extremely early onset Parkinson's disease.

The mechanism by which environmental insults such as inflammation/hypoxia and genetics combine in neurodevelopmental disease will be discussed below. It is also important to consider 


\section{Box 3 | Diagnosis and experimental tools.}

\section{EPIDEMIOLOGY}

Epidemiological studies linking prenatal insult with later neurodevelopmental disorders are subject to many difficulties, including the limitations of retrospective assessment of possible exposure to insult, and the years to decades elapsed between gestational insult and disease diagnosis. Early studies assessing the association between influenza and schizophrenia are an example of these difficulties, as assessments were made based on potential exposure to influenza during gestation (i.e., occurrence of an influenza epidemic during the pregnancy), rather than the actual presence of maternal infection (Brown and Derkits, 2010). More recent studies, that have utilized medical records and analyzed available blood samples, have found a significant risk of schizophrenia following inflammation in the first and second trimester of pregnancy. With conditions such as cerebral palsy, the successful outcome of epidemiological studies is more attainable. Due to the relatively early age of clinical diagnosis, as well as multiple neuropathologies that can be identified with imaging technology, it is possible for studies such as the ELGANS study (O'Shea et al., 2009; Leviton et al., 2011) to determine the links between multiple environmental insults, extreme prematurity, and risk of developing cerebral palsy or mental retardation in large cohort groups with well-defined assessment criteria.

\section{IMAGING}

Imagining modalities have been utilized to provide a whole brain view of neurodevelopmental disorders. The results from these studies, while advantageous, highlight the difficulty of determining the etiology of these disorders (Anagnostou and Taylor, 2011). Changes in the brain are generally subtle, requiring extensive group comparison with carefully controlled age-matched groups, and the origins of changes in signal are generally difficult to determine. For example, progressive loss of cortical gray matter is observed in cases of child-onset schizophrenia, but from MRI images it is currently difficult to determine whether these changes are of neuronal origin (e.g., increased synaptic pruning), or are due to changes in astrocytes, vasculature, or myelination of the affected cortical regions. Histological comparisons from autopsy may partly aid this analysis, although in the case of schizophrenia samples are generally late-stage disease and confounded by a variety of treatment and life-style choices (Toga et al., 2006). However, imaging techniques such as MRI, PET, and photo-acoustic ultrasound are now available with good resolution for small animals. The use of these together with standard histological assessments may allow links to be made between the structure and function of the brain in animal models and equivalent human clinical conditions.

\section{BEHAVIOR}

Deciphering how risk factors act on brain development that result in altered circuits, and subsequently influence the behavioral symptoms, is the real challenge of psychiatric research. Endophenotype is a psychiatric concept to divide behavioral symptoms into more stable phenotypes with a clear genetic connection. However, the involvement of distinct genes, which could underlie certain endophenotypic traits, in neural development is very often not known. Systematically examining the composition, morphology, connectivity of the brain is very rarely linked up to particular structure or cell types that make up circuits underlying behavioral endophenotypes in animal models. Nevertheless, animal models of behavior will remain valuable tools for the investigation of altered brain circuits (Amann et al., 2010).

the timing of insult in relation to the stages of brain development. The term "window of vulnerability" is commonly used when considering developmental neurological injury. However, it is not yet clear if this vulnerability is intrinsic to specific periods of development (e.g., proliferation or synapse formation), and therefore may move from region to region along with the normal developmental gradients of these processes. Alternatively, it has been suggested that different cells may become selectively vulnerable to damage as a result of the different intrinsic maturation process. An example of this are subplate neurons, which are thought to have increased vulnerability to injury in the prenatal human due to an early birth date and therefore earlier maturation of glutamate receptor populations (Furuta and Martin, 1999; Talos et al., 2006; Nguyen and McQuillen, 2010). This leads to increased sensitivity to excitotoxicity at a time of development where there is an increased risk of hypoxic-ischemic injury.

Cerebral palsy provides an example of the consequence of the stage of brain maturity at the time of insult on subsequent neuropathology. Injury at term, e.g., umbilical cord asphyxia during delivery, causes cerebral palsy with a typical pattern of gray matter loss, as well as damage to the hippocampus and cerebellum. Whereas preterm injury, leading to cerebral palsy, is generally associated with white matter and subcortical gray matter damage (Gunn and Bennet, 2009; Volpe, 2009). There are a few confounding maturation steps that underlie these differences in regional damage. White matter is beginning to be myelinated in the preterm period in humans, and specific populations of precursor oligodendrocytes have been shown to be particularly susceptible to damage, which corresponds to this period. In contrast, areas of term damage are typically described as "watershed" damage, indicating that these brain regions are at the edge of the vascular zones, therefore increasing susceptibility to hypoxic damage (Gunn and Bennet, 2009; Volpe, 2009). In preterm white matter, similar watershed regions have been suggested due to the pattern of vascular development, however, it was determined that differences in vascular blood flow could not account for the different magnitude of damage in the region (McClure et al., 2008). Therefore, the different patterns of damage have been associated with selective sensitivities of developing cells at the time of insult. This is an example whereby different insults, at different stages of brain development can cause distinct, but related neuropathologies which contribute to the one clinical diagnosis.

\section{GENETICS}

The genetic regulation of brain development is extremely complicated, with a wide number of genes regulating proliferation and differentiations states, as well as more subtle aspects of neurological function, such as signaling pathways and receptor function. 
Altered neurological development leads to a variety of subtle or complicated behavioral dysfunctions, from slight mental retardation to gross motor and cognitive deficits. A number of genetic variants have been associated with these general disorders, as well as specific neurodevelopmental diseases. For example, a large number of gene variants associated with increased risk of autism spectrum disorders (ASDs) have a wide range of functions in the central nervous system and are associated with a variety of other neurological disorders (Aldinger et al., 2011). Congenital neurological disorders due to genetic variation may have a subtle neuropathology, such as for autism, or may be associated with gross changes in the brain, such as for microcephaly.

Primary recessive microcephaly affects approximately 1:10,000 people, and is classified based on small brain size and altered gyrations of the cerebral cortex (either lissencephaly or polymicrogyria) that are present at birth (Abuelo, 2007). The genetic basis of this condition has been clearly linked to a number of mutations that all affect neural progenitors (Buchman et al., 2011; Mahmood et al., 2011; Poulton et al., 2011). The function of the abnormal spindle microcephaly (APSM) gene may occur directly through the regulation of the mitotic spindle and indirectly by modulating the Wnt signaling pathway (Buchman et al., 2011). Tbr2 is another gene that normally regulates proliferation within the developing cortex, where gene manipulation has been associated with microcephaly in experimental models (Arnold et al., 2008; Sessa et al., 2008) and in clinical cases of microcephaly in humans (Baala et al., 2007).

Inhibitory transmission is crucial for normal cortical function and its defects are associated with a variety of neurological and psychiatric disorders, including autism (Levitt, 2005), schizophrenia (Lewis et al., 2005), and epilepsy (Noebels, 2003). The pathobiology of schizophrenia remains poorly understood, but genetic and anatomical studies are beginning to indicate the complicated neuropathology. Recently identified epigenetic changes in GAD67 and reelin genes support the GABAergic hypothesis of schizophrenia (O'Connell et al., 2011). Post-mortem studies have also revealed reductions in inhibitory neurotransmission markers in schizophrenics (Volk et al., 2000); although this may not be the case in all subjects and modern hypotheses focus on abnormal interneuronal connectivity rather than simply insufficient numbers of cells (Marín, 2012), these observations are nonetheless suggestive of developmental abnormalities (Harrison and Weinberger, 2005). For instance, Disrupted in Schizophrenia 1 (DISC1) mutations are known to cause familial schizophrenia (Millar et al., 2000). DISC1 appears to function in cell migration among other pathways, as mouse models with DISC1 inhibition show reduced migration of both developing pyramidal cells (Kamiya et al., 2005) and MGE-derived interneurons (Steinecke et al., 2012). Neuregulin 1 (NRG1) and its receptor ErbB4, both schizophrenia risk genes (Stefansson et al., 2002, 2003), are also involved in migration: ErbB4 mutant mouse cerebellar cultures exhibit reduced granule cell migration along radial glia (Rio et al., 1997) and electroporations of dominantnegative ErbB4 into the MGE prevent migration to the cortex, whereas heterologous expression of NRG1 induces migration toward the expressing cells in vitro and in vivo (Flames et al., 2004). There are numerous other examples of development-related schizophrenia risk gene such as Tcf4 and CNTNAP2 (Blake et al., 2010). However, as most risk-conferring polymorphisms are intronic, their functions and relevance to disease mechanisms are not well characterized. Moreover, DISC1 has not been demonstrated to have significant association with schizophrenia in genome-wide association studies (GWAS). It is likely that there are numerous endophenotypes in schizophrenia with different underlying genetic causes, but these have not yet been well defined.

One of the GWAS results for schizophrenia has been the MHC region (Stefansson et al., 2009), suggesting the involvement of immune mechanisms in the pathogenesis. This in conjunction with the well-documented risk conferred by maternal infections and behavioral abnormalities in animal models (Patterson, 2009) would support an underlying immunopathology, but the GWAS results implicating MHC genes have been criticized for using intergenic single-nucleotide polymorphisms (SNPs) in many cases - although the SNPs are assumed to be in linkage disequilibrium with the encoded genes, this cannot exclude noncoding RNA involvement in schizophrenia; moreover, the genic SNPs that have shown significant associations have not been thoroughly characterized in terms of their function (Gejman et al., 2011). Associations have also been found between schizophrenia and the pro-inflammatory cytokines interleukin $1 \beta$ (Xu and He, 2010), interleukin 6 (Paul-Samojedny et al., 2010), and the anti-inflammatory interleukin 10 (Bocchio Chiavetto et al., 2002), further supporting the involvement of inflammatory pathways, even if the pathomechanisms through which these alleles influence disease development are obscure.

Autism spectrum disorders share some of the problems of schizophrenia: numerous preliminary gene associations have not been replicated, and the pathobiology is uncertain and likely to be heterogeneous. In this case, the evidence for a developmental defect is much clearer, given its early onset. This is reflected in the functions of implicated genes. For instance, neuroligin 4 was identified in a family with X-linked mental retardation and autism (Laumonnier et al., 2004). Neuroligins are thought to function in presynaptic development, and they interact with neurexins to regulate postsynaptic development (Dean and Dresbach, 2006) - neurexin 1 has also been associated with ASDs (Kim et al., 2008) and schizophrenia (Rujescu et al., 2009), consistent with hypotheses of abnormal synaptic development in these disorders. Copy number variations and mutations in SHANK2 and SHANK3, synaptic scaffolding genes, have been linked to ASDs (Durand et al., 2007; Berkel et al., 2010), as have $\mathrm{K}^{+}$channel regulation associated genes such as DPP6 and DPP10 (Marshall et al., 2008), all indicative of synaptic dysfunction in autism. Cell migration pathways have been implicated by a genome-wide study for copy number variations, which produced significant results for cell adhesion genes with presumptive migratory functions including ASTN2 (Glessner et al., 2009). CNTNAP2, another ASD risk gene (Arking et al., 2008), has also been characterized as crucial for normal neuronal migration: CNTNAP2 ${ }^{-1-}$ mice show behavioral abnormalities, ectopic neurons in the corpus callosum (indicative of defective migration) and reduced numbers of GABAergic interneurons among other abnormalities (Peñagarikano et al., 2011). MeCP2, the gene 
affected in Rett syndrome featuring autism and other developmental defects, also impairs GABAergic transmission: mice exhibit behavioral defects suggestive of ASD in both full KOs and interneuron-specific KOs of MeCP2 (Chao et al., 2010). Overall, it can be concluded that both autism and schizophrenia share developmental origins and synaptic dysfunction as their main pathways, but these are not independent of environmental influences (Harrison and Weinberger, 2005; Bill and Geschwind, 2009).

In autism and schizophrenia, immune regulating gene variants have also been heighted as disease risk factors. In particular there are multiple lines of evidence linking variants in DRB1 alleles of the human leukocyte antigen (HLA) with both of these neurodevelopmental conditions (Crespi and Thiselton, 2011). It is hypothesized that these genetic variants contribute to disease ontology through modulation of the normal immune signaling in brain development. Inflammation during pregnancy has also been linked to both these neurological disorders in epidemiology (see below), indicating that genetic and environmental variations can affect normal development, and leading to disease pathology.

\section{INFLAMMATION}

A variety of genes with known roles in the immune system have recently been found in progenitor cells in the developing cortex. Toll-like receptors are a group of pathogen recognition receptors, that respond to bacteria (e.g., TLR2 and TLR4) and viral (e.g., TLR3) presence (Medzhitov, 2007). These receptors mediate a proinflammatory response through NF- $\mathrm{B}$, and have also been found to be activated by tissue damage. Two recent studies have shown the constitutive expression of TLR 2 and TLR 3 in progenitor cells within the ventricular zone in early and intermediate telencephalic development (Lathia et al., 2008; Okun et al., 2010). In both cases activation of the receptor causes a decrease in proliferation, but in the case of TLR2 the absence of the constitutive presence, in TLR2 ${ }^{-1-}$ mice, does not affect proliferation or differentiation of progenitors (Okun et al., 2010), while in TLR3 ${ }^{-1-}$ mice there is an increase in proliferation in the VZ and SVZ (Lathia et al., 2008). The presence of these and other inflammatory mediating receptors in the neural progenitor cells provide a potential mechanism for recent observations of inflammatory induced damage to the developing brain. Many studies have shown behavioral changes following maternal immune activation during early gestation. The pathology underlying these behavioral changes has been unclear; however, our recent study has shown that maternal inflammation induced at in the early phases of telencephalic development causes decreased proliferation in the VZ (Stolp et al., 2011; Figure 5). Part of the mechanism for this may be the activation of the TLRs, although this interaction has not yet been described. What has been reported is a decrease in $\beta$-catenin at the ventricular surface (Stolp et al., 2011), which may also contribute to the decreased proliferation in this model, and suggests that a complex interplay of many factors that normally regulate proliferation may be affected by maternal inflammation. Interestingly, the maternal inflammatory response that produces reduced ventricular proliferation at E13.5 in the mouse does not appear to significantly affect the proliferation of basal progenitors within the SVZ (Stolp et al., 2011; Figure 5). This suggests that the regulation of proliferation in the
SVZ may be different from the VZ, or that the mechanism of entry of inflammatory molecules into the brain may selectively affect one population and not the other. The basal progenitors in the SVZ are closely associated with the blood vessels that make up the ventricular vascular plexus in early development, while the VZ progenitors have close contact with the CSF in the ventricular system. In the adult brain, systemic inflammation has been found to alter transcription of acute phase proteins and adhesion molecules in the choroid plexus and there is an increase in interleukin- 6 and the chemokine CCL2 in the CSF (Marques et al., 2009). It is possible, though currently unstudied, that systemic inflammation may also cause increased cytokine levels in fetal CSF that directly regulate proliferation in the $\mathrm{VZ}$.

An alternative mechanism for inflammatory regulation of progenitor proliferation is a modification in the normal function of microglia. The work of Roumier et al. (2008) suggests that inflammatory activation has the same effect as microglial lossof-function in the DAP $12^{\mathrm{KI}}$ mouse. They provide evidence to suggest that the loss-of-function mutation actually causes minor activation of the microglia and cytokine production that modulates neuronal function, which can be recapitulated at E15 in the mouse by induced maternal inflammation. In the developing brain microglia have a typically amoeboid morphology associated with their entry from the systemic circulation and subsequent differentiation. It has been hypothesized that this morphology conveys a reactive phenotype and that inflammation or injury in the developing brain may be more severe than in the adult brain, where microglia need to be reactivated from a "resting" state. At later stages of brain development inflammation has been associated with interneuron dysfunction. For instance, neonatal exposure to LPS is associated with reduced parvalbumin immunoreactivity in the CA1-CA3 region (but not the prefrontal cortex) with later defects in object recognition (Jenkins et al., 2009), and viral infection at $\mathrm{P} 4$ can cause a gradual loss of hippocampal interneurons (Pearce et al., 2000). Such changes can have an indirect effect on the cortex: one recent study showed that neonatal intrahippocampal LPS in rat increases cytokine expression in the adult hippocampus and cortex, impairs dopaminergic modulation of prefrontal interneurons and causes a deficit in prepulse inhibition (Feleder et al., 2010). Inflammation during fetal development has been most strongly linked with brain damage leading to cerebral palsy. Many studies have shown that maternal inflammation in the later part of the second trimester, or equivalent in animal models, causes an array of white matter injury, including diffuse demyelination and cystic lesions (Rezaie and Dean, 2002), which correspond well to the periventricular leukomalacia that is a common MRI observation in cerebral palsy (Counsell et al., 2003). It seems that the susceptibility of the white matter to damage is largely due to the presence of pre-oligodendrocytes that have a low damage threshold (Back and Rivkees, 2004).

As one of the links between immune and CNS development, there is a plethora of evidence for various cytokines regulating CNS development. For instance, CSF-1 is a cytokine involved in monocyte survival and proliferation, but null mutations also cause defects in cortical circuitry (Michaelson et al., 1996). The gp130 family cytokines such as LIF and CTNF promote radial glial cell renewal and ventricular zone proliferation in rodents (Deverman 


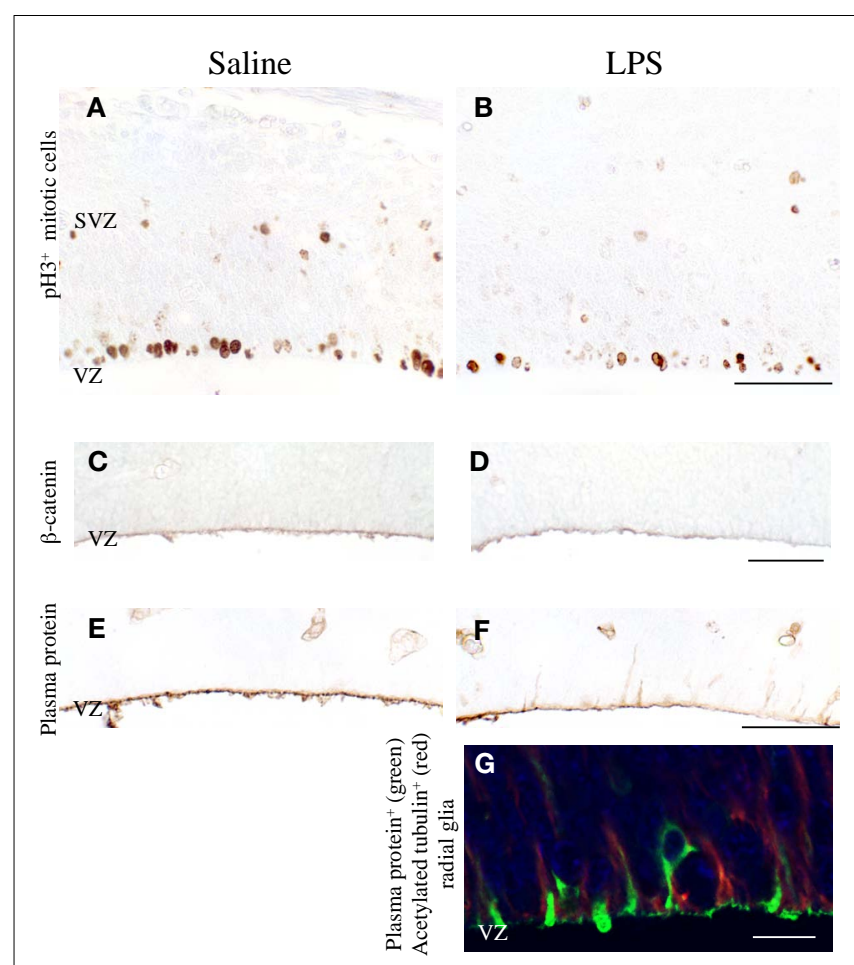

FIGURE 5 | Effect of maternal inflammation on the ventricular zone at E13. Maternal inflammation at E13 has profound effects on cortical development. There is a decrease in proliferation in the ventricular zone $(\mathbf{A}, \mathbf{B})$. As well as this, there is a disruption of the ventricular surface, indicated by decreased $\beta$-catenin immunoreactivity $(\mathbf{C}, \mathbf{D})$ and uptake of proteins from the CSF (E,F), by acetylated tubulin positive radial glia $(\mathbf{G})$. Scale bars $=50 \mu \mathrm{m}$ for $(\mathbf{A}-\mathbf{F}), 10 \mu \mathrm{m}$ for $(\mathbf{G})$. Modified from Stolp et al. (2011).

and Patterson, 2009), but also astrogliogenesis in later development. However, this is mainly related to local expression within the developing CNS, rather than the inflammation-associated endocrine functions of cytokines, which have been associated with a wide variety of neurodevelopmental disorders including schizophrenia (Ellman and Susser, 2009), autism and periventricular leukomalacia (Deverman and Patterson, 2009). Due to the prevalence of IL-6/gp130 family cytokines acting in the developing brain, there has been substantial investigation of the contribution of IL- 6 of brain injury induced by maternal immune activation. IL-6 has been shown to increase in the fetal brain following many forms of early life systemic inflammation (Golan et al., 2005; Stolp et al., 2009), and there is some evidence that IL-6 in the maternal circulation can cross the placenta from mid-gestation (Dahlgren et al., 2006). The most compelling evidence for the important contribution of IL-6 to early life neurodevelopmental disorders is the work of Patterson and colleagues. In their recent paper (Smith et al., 2007), substantial evidence was present that IL-6 alone could stimulate long-term changes in neurological behavior and that inhibiting IL- 6 when inflammation is induced by a general immune mediator prevents these behavioral phenotypes. A further recent study also implicated maternal IL- 6 in influencing placental expression of immune- and endocrine-related genes, including factors known to influence fetal development such as growth hormone and insulin-like growth factor I (Hsiao and Patterson, 2011), which poignantly illustrates the interconnectedness of immune, endocrine, and CNS development.

\section{HYPOXIA-ISCHEMIA}

While the brain grows in a hypoxic environment, it is protected from extremes of hypoxia, as with many other organs, by vascular auto-regulation (Pearce, 2006). As part of normal brain function, neurovascular coupling allows distribution of nutrients in a spatial and temporal fashion to brain areas with the highest neuronal activity and, therefore, metabolic demand. This form of auto-regulation is typically due to the function of smooth muscle cells around the pial, penetrating and pre-capillary arterioles (Lok et al., 2007). However, at the level of the capillaries, pericytes and astrocytes have been found to have some contractile capacity and are able to regulate vessel diameter (Haydon and Carmignoto, 2006; Peppiatt et al., 2006). It is currently unclear how much this contributes to the vascular auto-regulation (discussed by Quaegebeur et al., 2011), and there is also currently limited data indicating when these auto-regulatory mechanisms are established. Clinical and experimental research demonstrated evidence of regulation during late stages of human pregnancy and pericyte- and astrocyte-induced contraction of capillary beds in postnatal rat brains (Peppiatt et al., 2006; Degani, 2009), suggesting that auto-regulatory mechanisms occur in the fourth phase of telencephalic development.

Hypoxic injury is generally considered to be associated with birth complications and neurodevelopmental injury such as cerebral palsy (Gunn and Bennet, 2009; Volpe, 2009). There has been a recognized difficulty in diagnosing consequences of antenatal oxygen deprivation as there is not a clear correlation with markers of oxygen deficit (e.g., acidosis, lactate levels) and later neuropathology (Gunn and Bennet, 2009). This is partly due to the protective mechanism of the brain and cerebrovascular system and the regenerative capacity of the still developing CNS (see below). However, despite the presence of auto-regulatory mechanisms, the clearest link between hypoxia-ischemia and brain injury is during this stage of brain development (Lou et al., 2004). White matter damage has been found to occur following inflammation or hypoxia-ischemia (Hagberg et al., 2002). The precursor oligodendrocytes are susceptible to damage at this stage of development (Back et al., 2001; Back and Rivkees, 2004) and number of studies have shown that high density of microglia within the white matter contributes to this injury, facilitating the immune activation of the susceptible oligodendrocyte precursors (Verney et al., 2010). It is likely that the mechanisms of injury in these two experimental conditions are linked, as hypoxia-ischemia can cause the production of inflammatory mediators and inflammation can cause an alteration in auto-regulation and potentially reduce oxygenation.

Astrocytes have been shown to undergo functional and structural long term changes following neonatal hypoxia/ischemia in the pig brain (Sullivan et al., 2010a,b). There are significant decreases in the average astrocyte size, number of processes, and length of processes following hypoxia-ischemia treatment. Furthermore, D-aspartate uptake studies revealed that 
the hypoxia-ischemia insult resulted in impaired astrocytes function, with significantly reduced clearance of the glutamate analog, D-aspartate. Sullivan et al. (2010b) argue that the initial reduction in astrocytes size and impaired function in the study are detrimental to the survival of neurons. Changes in the morphology of astrocytes have the potential to alter functions reliant on the location of astrocytic membrane proteins, for example the glutamate transporters located in close proximity to synapses play a role in clearing the excitatory amino acids preventing excitotoxicity (Sullivan et al., 2010b).

Subplate neurons have been suggested to be selectively sensitive to hypoxic-ischemic injury in postnatal rodents (McQuillen et al., 2003) and perinatal humans (Volpe, 2009) that might account for some behavioral deficits observed following hypoxic-ischemic injury. However, the majority of thalamic connections have been made by these stages of brain development, and no damage to these connections was observed following injury (McQuillen et al., 2003). It has recently been questioned whether the subplate is actually at increased sensitivity that other neurons in the cerebral cortex (Nguyen and McQuillen, 2010), with deficits in layer $\mathrm{V}$ also observed in autopsy studies of human periventricular leukomalacia (Andiman et al., 2010).

\section{DRUGS/TOXINS}

Unlike the relatively general actions of inflammation and hypoxia, a number of drugs and toxins appear to have very specific actions on the central nervous system, based on binding to channels or receptors within the brain. Lead is one example of this, where its presence within the brain appears to interfere with $\mathrm{Ca}^{2+}$ entry into synaptic terminals, which normally facilitates neurotransmitter release (Suszkiw, 2004). Interestingly, this appears to have an immediate effect, as well as a long-term, developmental effect. This may be due to the inhibition of NMDA receptor-dependent BDNF signaling, that is important for the stabilization of synaptic regions during presynaptic development (Neal et al., 2010). The $\mathrm{CB}_{1}$-receptor is differentially regulated during neurogenic commitment, and there is evidence suggesting that cannabis exposure can affect fate regulation of cells in the developing brain by switching the balance of normal endocannabinoid signaling (Keimpema et al., 2011). Cocaine exposure during the prenatal period appears to have long term consequences on dopamine transporter function (Harvey, 2004) as well as impairing tangential and radial migration within the developing telencephalon (Lee et al., 2011; McCarthy et al., 2011), providing a possible double-hit that results in long-term behavioral deficits.

Ethanol is another environmental toxin with known effects on the central nervous system, and is currently considered to be the major preventable cause of mental retardation worldwide (Centre of Disease Control). In the cortex, observed changes include ectopias and microgyri-like structures and a general reduction in cortical volume (see Fukui and Sakata-Haga, 2009 for review). These changes, and the critical period identified for ethanol-induced microcephaly (Guerri, 2002), suggest early stages of cortical development are disrupted, with the radial progenitors the main target for the effects of ethanol. In support of this hypothesis, a decrease proliferation of these progenitors has been observed in a number of models of prenatal ethanol exposure
(Rubert et al., 2006), as well as increased death of this population (Rubert et al., 2006; Aronne et al., 2008). There is also a reduction in the ability of the radial progenitors to differentiate into neurons and glia in an ex vivo assessment of progenitor function following prenatal ethanol exposure (Rubert et al., 2006). Interestingly, a recent study suggests that alcohol induces inflammation via activation of TLR4 (Alfonso-Loeches et al., 2010), which could mean that inflammation and ethanol exposure have similar underlying mechanisms of damage in the early developing brain.

\section{GENE-ENVIRONMENT INTERACTIONS}

The original evidence supporting gene-environmental interactions in neurodevelopmental disorders were based largely on observations of disease incidence. For example, siblings of autistic patients have approximately a $3-8 \%$ risk of disease incidence. This risk increases to $10 \%$ in non-identical twins and to $60-90 \%$ in identical twins (Parker-Athill and Tan, 2010). The incidence in siblings suggests a genetic component of the disease, while the increased incidence in non-identical twins highlights the important contribution of a shared maternal environment. The high concordance in identical twins, where gene and maternal environment are shared, has now been recognized not just to indicate genetic susceptibility, but also to highlight the important of the gene-environment interaction (van Os et al., 2010).

There are two main mechanisms by which gene-environment interactions can contribute to disease etiology. The first is a direct interaction, where a genetic polymorphism or copy number variant increases damage (or confers protection) after an environmental insult. The second is the ability of an environmental insult to produce an epigenetic change, potentially causing a long-term modulation of gene function (Van Winkel et al., 2010). There is evidence for both of these interaction paradigms in a number of neurological and mental disorders.

There are, as yet, few experimental studies testing the link between genes and environment, although those that do, using a number of outcome measures, have all indicated a synergistic effect of genetic modification is combined with environmental challenge, above and beyond what was observed with a single challenge (Oliver, 2011). One example, relevant for the etiology of schizophrenia is the combination of early life inflammation and a DISC1 mutation, which has been recognized in a number of schizophrenic patients. PolyI:C induced inflammation in both prenatal and postnatal mice carrying a DISC1 mutation is associated with a number of behavioral changes that are not observed in the DISC1 animals or polyI:C animals alone (Abazyan et al., 2010; Ibi et al., 2010).

The neurodevelopmental injury models of schizophrenia have also lead to the identification of new candidate genes for increased disease risk. Considering the increased risk of schizophrenia associated with perinatal hypoxia, Schmidt-Kastner et al. (2012) reevaluated a number of GWAS and CNV studies to determine if genes associated with the hypoxic-ischemic response are altered in the schizophrenic patients. Their findings substantially supported this hypothesis, identifying a number of additional gene modifications that may increase the risk of schizophrenia following birth complications, and supporting the earlier work of 
Nicodemus et al. (2008), who showed a significant interaction between hypoxia-ischemia genes and obstetric complications in a cohort of schizophrenia patients.

A later life example of gene-environment interaction is that of the association between cannabis use and psychosis. Caspi et al. (2005) conducted a longitudinal study on an epidemiological birth cohort and found that presence of a polymorphism in the COMT gene in combination with adolescent cannabis use increased the risk of adult-hood psychosis. The presence of the polymorphism explains the strong association between cannabis use and psychosis while also accounting for the small risk of psychosis in cannabis users in general.

Epigenetic changes in neurological disease are less well defined in neuropathology, and the potential heritability of the epigenetic change confounds the gene-environment calculation. However, altered histone methylations (one of the key forms of epigenetic regulation) have been described in brains from patients that had been diagnosed with schizophrenia or depression (Peter and Akbarian, 2011). Drug exposure (e.g., to methamphetamine) and stress are examples of environmental challenges that my cause epigenetic changes, and have been linked to changes in DNA methylation in the brains of schizophrenic patients and relevant animal models (Oh and Petronis, 2008). Additionally, transcriptional repressor MeCP2 has been identified in autism, with gene silencing

\section{REFERENCES}

Aaku-Saraste, E., Hellwig, A., and Huttner, W. B. (1996). Loss of occludin and functional tight junctions, but not ZO-1, during neural tube closure-remodeling of the neuroepithelium prior to neurogenesis. Dev. Biol. 180, 664-679.

Abazyan, B., Nomura, J., Kannan, G., Ishizuka, K., Tamashiro, K. L., Nucifora, F., Pogorelov, V., Ladenheim, B., Yang, C., Krasnova, I. N., Cadet, J. L., Pardo, C., Mori, S., Kamiya, A., Vogel, M. W., Sawa, A., Ross, C. A., and Pletnikov, M. V. (2010). Prenatal interaction of mutant discl and immune activation produces adult psychopathology. Biol. Psychiatry 68, 1172-1181.

Abuelo, D. (2007). Microcephaly syndromes. Semin. Pediatr. Neurol. 14, 118-127.

Ahmed, O. M., El-Gareib, A. W., ElBakry, A. M., Abd El-Tawab, S. M., and Ahmed, R. G. (2008). Thyroid hormones states and brain development interactions. Int. J. Dev. Neurosci. 26, 147-209.

Alcamo, E. A., Chirivella, L., Dautzenberg, M., Dobreva, G., Farinas, I., Grosschedl, R., and McConnell, S. K. (2008). Satb2 regulates callosal projection neuron identity in the developing cerebral cortex. Neuron 57, 364-377.

Aldinger, K. A., Plummer, J. T., Qiu, S., and Levitt, P. (2011). SnapShot: genetics of autism. Neuron 72, 418-418, e411.

Alfonso-Loeches, S., Pascual-Lucas, M., Blanco, A. M., Sanchez-Vera, I., and Guerri, C. (2010). Pivotal role of TLR4 receptors in alcohol-induced neuroinflammation and brain damage. J. Neurosci. 30, 8285-8295.

Allendoerfer, K. L., and Shatz, C. J. (1994). The subplate, a transient neocortical structure: its role in the development of connections between thalamus and cortex. Annu. Rev. Neurosci. 17, 185-218.

Amann, L. C., Gandal, M. J., Halene, T. B., Ehrlichman, R. S., White, S. L., McCarren, H. S., and Siegel, S. J. (2010). Mouse behavioral endophenotypes for schizophrenia. Brain Res. Bull. 83, 147-161.

Anagnostou, E., and Taylor, M. J. (2011). Review of neuroimaging in autism spectrum disorders: what have we learned and where we go from here. Mol. Autism 2, 4.

Anderson, S. A., Marin, O., Horn, C., Jennings, K., and Rubenstein, J. L. (2001). Distinct cortical migrations from the medial and lateral ganglionic eminences. Development 128, 353-363.

Andiman, S. E., Haynes, R. L., Trachterth, R. D., Volpe, J. J., and Kinney, H. C. (2010). The cerebral cortex overlying periventricular leukomalacia: analysis of pyramidal neurons. Brain Pathol. 20, 803-814. enberg, F. L., Billiards, S. S., Folk-

produced by this mechanism linked to changes in neuronal structure (Currenti, 2010). It is likely that epigenetic modification of gene function will be increasingly recognized as a key contributor to neurological disorders as our scientific investigations continue in this area.

\section{CONCLUSIONS}

It is clear that there are a number of factors that contribute to neurodevelopmental disorders. When considering which are the most important in predicting neuropathology following insult it is necessary to consider the likelihood that multiple "windows of vulnerability" exist within the developing brain. These are likely to be dependent on the type and severity of the environmental insult and the genetic background of the individual. The task to decipher the links between genetic susceptibility and environmental insults is hindered by the fact that barrier functions, inflammatory, and endocrine factors have to be taken into account along with brain development. These will have to be considered in different combinations, rather than in isolation. Our current approaches are not broad enough. We are determined to link diseases to a single genetic or environmental insult. Instead, a wide variety of broadly linked functional systems have been identified as possibly effected, and the genes involved in various stages of neuronal development might be just a small part of the puzzle.

Anthony, D. C., Bolton, S. J., Fearn, S. and Perry, V. H. (1997). Agerelated effects of interleukin-1 beta on polymorphonuclear neutrophil-dependent increases in blood-brain barrier permeability in rats. Brain 120, 435-444.

Antony, J. M., Paquin, A., Nutt, S. L., Kaplan, D. R., and Miller, F. D. (2011). Endogenous microglia regulate development of embryonic cortical precursor cells. J. Neurosci. Res. 89, 286-298.

Arking, D. E., Cutler, D. J., Brune, C. W., Teslovich, T. M., West, K., Ikeda, M., Rea, A., Guy, M., Lin, S., Cook, E. H., and Chakravarti, A. (2008). A common genetic variant in the neurexin superfamily member cntnap 2 increases familial risk of autism. Am. J. Hum. Genet. 82, 160-164.

Arnold, S. J., Huang, G. J., Cheung, A. F., Era, T., Nishikawa, S., Bikoff, E. K., Molnar, Z., Robertson, E. J., and Groszer, M. (2008). The T-box transcription factor Eomes/Tbr2 regulates neurogenesis in the cortical subventricular zone. Genes Dev. 22, 2479-2484.

Aronne, M. P., Evrard, S. G., Mirochnic, S., and Brusco, A. (2008). Prenatal ethanol exposure reduces the expression of the transcriptional factor Pax6 in the developing rat brain. Ann. N.Y. Acad. Sci. 1139, 478-498.
Ashdown, H., Dumont, Y., Ng, M., Poole, S., Boksa, P., and Luheshi, G. N. (2006). The role of cytokines in mediating effects of prenatal infection on the fetus: implications for schizophrenia. Mol. Psychiatry 11, 47-55.

Avignone, E., Ulmann, L., Levavasseur, F., Rassendren, F., and Audinat, E. (2008). Status epilepticus induces a particular microglial activation state characterized by enhanced purinergic signaling. J. Neurosci. 28, 9133-9144.

Baala, L., Briault, S., Etchevers, H. C. Laumonnier, F., Natiq, A., Amiel, J., Boddaert, N., Picard, C., Sbiti, A., Asermouh, A., Attie-Bitach, T., Encha-Razavi, F., Munnich, A., Sefiani, A., and Lyonnet, S. (2007). Homozygous silencing of T-box transcription factor EOMES leads to microcephaly with polymicrogyria and corpus callosum agenesis. Nat. Genet. 39, 454-456.

Back, S. A., Luo, N. L., Borenstein, N. S., Levine, J. M., Volpe, J. J., and Kinney, H. C. (2001). Late oligodendrocyte progenitors coincide with the developmental window of vulnerability for human perinatal white matter injury. J. Neurosci. 21, 1302-1312.

Back, S. A., and Rivkees, S. A. (2004). Emerging concepts in periventricular white matter injury. Semin. Perinatol. 28, 405-414. 
Badawi, N., Dixon, G., Felix, J. F., Keogh, J. M., Petterson, B., Stanley, F. J., and Kurinczuk, J. J. (2006). Autism following a history of newborn encephalopathy: more than a coincidence? Dev. Med. Child Neurol. 48, 85-89.

Barker, D. J. (2007). The origins of the developmental origins theory. $J$. Intern. Med. 261, 412-417.

Barnabe-Heider, F., Wasylnka, J. A., Fernandes, K. J., Porsche, C., Sendtner, M., Kaplan, D. R., and Miller, F. D. (2005). Evidence that embryonic neurons regulate the onset of cortical gliogenesis via cardiotrophin-1. Neuron 48, 253-265.

Bauer, H. C., Steiner, M., and Bauer, H. (1992). Embryonic development of the cns microvasculature in the mouse: new insights into the structural mechanisms of early angiogenesis. EXS 61, 64-68.

Belgard, T. G., Marques, A. C., Oliver, P. L., Abaan, H. O., Sirey, T. M., Hoerder-Suabedissen, A., GarciaMoreno, F., Molnar, Z., Margulies, E. H., and Ponting, C. P. (2011). A transcriptomic atlas of mouse neocortical layers. Neuron 71, 605-616.

Berbel, P., and Innocenti, G. M. (1988). The development of the corpus callosum in cats: a light- and electronmicroscopic study. J. Comp. Neurol. 276, 132-156.

Berbel, P., Mestre, J. L., Santamaria, A., Palazon, I., Franco, A., Graells, M., Gonzalez-Torga, A., and De Escobar, G. M. (2009). Delayed neurobehavioral development in children born to pregnant women with mild hypothyroxinemia during the first month of gestation: the importance of early iodine supplementation. Thyroid 19, 511-519.

Berkel, S., Marshall, C. R., Weiss, B., Howe, J., Roeth, R., Moog, U., Endris, V., Roberts, W., Szatmari, P., Pinto, D., Bonin, M., Riess, A., Engels, H., Sprengel, R., Scherer, S. W., and Rappold, G. A. (2010). Mutations in the shank2 synaptic scaffolding gene in autism spectrum disorder and mental retardation. Nat. Genet. 42, 489-491.

Bill, B. R., and Geschwind, D. H. (2009). Genetic advances in autism: heterogeneity and convergence on shared pathways. Curr. Opin. Genet. Dev. 19, 271-278.

Bilbo, S. D., Smith, S. H., and Schwarz, J. M. (2012). A lifespan approach to neuroinflammatory and cognitive disorders: a critical role for glia. J. Neuroimmune Pharmacol. 7, 24-41.

Bjartmar, L., Huberman, A. D., Ullian, E. M., Renteria, R. C., Liu, X.,
Xu, W., Prezioso, J., Susman, M. W., Stellwagen, D., Stokes, C. C., Cho, R., Worley, P., Malenka, R. C., Ball, S., Peachey, N. S., Copenhagen, D., Chapman, B., Nakamoto, M., Barres, B. A., and Perin, M. S. (2006). Neuronal pentraxins mediate synaptic refinement in the developing visual system. J. Neurosci. 26, 6269-6281.

Blake, D. J., Forrest, M., Chapman, R. M., Tinsley, C. L., O’Donovan, M. C. and Owen, M. J. (2010). Tcf4, schizophrenia, and pitt-hopkins syndrome. Schizophr. Bull. 36, 443-447.

Bocchio Chiavetto, L., Boin, F., Zanardini, R., Popoli, M., Michelato, A., Bignotti, S., Tura, G. B., and Gennarelli, M. (2002). Association between promoter polymorphic haplotypes of interleukin-10 gene and schizophrenia. Biol. Psychiatry 51, 480-484.

Bonnin, A., Goeden, N., Chen, K., Wilson, M. L., King, J., Shih, J. C., Blakely, R. D., Deneris, E. S., and Levitt, P. (2011). A transient placental source of serotonin for the fetal forebrain. Nature 472, 347-350.

Brand, T. (2003). Heart development: molecular insights into cardiac specification and early morphogenesis. Dev. Biol. 258, 1-19.

Breunig, J. J., Haydar, T. F., and Rakic, P. (2011). Neural stem cells: historical perspective and future prospects. Neuron 70, 614-625.

Brinton, R. D. (2009). Estrogen-induced plasticity from cells to circuits: predictions for cognitive function. Trends Pharmacol. Sci. 30, 212-222.

Britanova, O., De Juan Romero, C., Cheung, A., Kwan, K. Y., Schwark, M., Gyorgy, A., Vogel, T., Akopov, S., Mitkovski, M., Agoston, D., Sestan, N., Molnar, Z., and Tarabykin, V. (2008). Satb2 is a postmitotic determinant for upper-layer neuron specification in the neocortex. Neuron 57, 378-392.

Brown, A. S., and Derkits, E. J. (2010). Prenatal infection and schizophrenia: a review of epidemiologic and translational studies. Am. J. Psychiatry 167, 261-280.

Buchman, J. J., Durak, O., and Tsai, L. H. (2011). ASPM regulates Wnt signaling pathway activity in the developing brain. Genes Dev. 25, 1909-1914.

Butt, S. J., Fuccillo, M., Nery, S., Noctor, S., Kriegstein, A., Corbin, J. G., and Fishell, G. (2005). The temporal and spatial origins of cortical interneurons predict their physiological subtype. Neuron 48, 591-604.

Bystron, I., Blakemore, C., and Rakic, P. (2008). Development of the human cerebral cortex: Boulder Committee revisited. Nat. Rev. Neurosci. 9, 110-122.

Calegari, F., Haubensak, W., Haffner, C. and Huttner, W. B. (2005). Selective lengthening of the cell cycle in the neurogenic subpopulation of neural progenitor cells during mouse brain development. J. Neurosci. 25, 6533-6538.

Carmeliet, P., Ferreira, V., Breier, G., Pollefeyt, S., Kieckens, L., Gertsenstein, M., Fahrig, M., Vandenhoeck, A., Harpal, K., Eberhardt, C. Declercq, C., Pawling, J., Moons, L., Collen, D., Risau, W., and Nagy, A. (1996). Abnormal blood vessel development and lethality in embryos lacking a single VEGF allele. Nature 380, 435-439.

Caspi, A., Moffitt, T. E., Cannon, M., McClay, J., Murray, R., Harrington, H., Taylor, A., Arseneault, L., Williams, B., Braithwaite, A., Poulton, R., and Craig, I. W. (2005). Moderation of the effect of adolescent-onset cannabis use on adult psychosis by a functional polymorphism in the catechol-omethyltransferase gene: longitudinal evidence of a gene $\mathrm{x}$ environment interaction. Biol. Psychiatry 57, 1117-1127.

Chao, H. T., Chen, H., Samaco, R. C., Xue, M., Chahrour, M., Yoo, J., Neul, J. L., Gong, S., Lu, H. C., Heintz, N., Ekker, M., Rubenstein, J. L., Noebels, J. L., Rosenmund, C., and Zoghbi, H. Y. (2010). Dysfunction in gaba signalling mediates autismlike stereotypies and rett syndrome phenotypes. Nature 468, 263-269.

Chen, B., Wang, S. S., Hattox, A. M., Rayburn, H., Nelson, S. B., and McConnell, S. K. (2008). The Fezf2Ctip2 genetic pathway regulates the fate choice of subcortical projection neurons in the developing cerebral cortex. Proc. Natl. Acad. Sci. U.S.A. 105, 11382-11387.

Chen, S. K., Tvrdik, P., Peden, E., Cho, S., Wu, S., Spangrude, G., and Capecchi, M. R. (2010). Hematopoietic origin of pathological grooming in Hoxb8 mutant mice. Cell 141, 775-785.

Cheng, A., Scott, A. L., Ladenheim, B., Chen, K., Ouyang, X., Lathia, J. D., Mughal, M., Cadet, J. L., Mattson, M. P., and Shih, J. C. (2010). Monoamine oxidases regulate telencephalic neural progenitors in late embryonic and early postnatal development. J. Neurosci. 30, 10752-10762.

Christopherson, K. S., Ullian, E. M., Stokes, C. C., Mullowney, C. E., Hell, J. W., Agah, A., Lawler, J.,
Mosher, D. F., Bornstein, P., and Barres, B. A. (2005). Thrombospondins are astrocyte-secreted proteins that promote CNS synaptogenesis. Cell 120, 421-433.

Cirulli, F., Francia, N., Berry, A., Aloe, L., Alleva, E., and Suomi, S. J. (2009). Early life stress as a risk factor for mental health: role of neurotrophins from rodents to non-human primates. Neurosci. Biobehav. Rev. 33, 573-585.

Clowry, G., Molnar, Z., and Rakic, P. (2010). Renewed focus on the developing human neocortex. J. Anat. 217, 276-288.

Cossart, R. (2011). The maturation of cortical interneuron diversity: how multiple developmental journeys shape the emergence of proper network function. Curr. Opin. Neurobiol. 21, 160-168.

Counsell, S. J., Allsop, J. M., Harrison, M. C., Larkman, D. J., Kennea, N. L., Kapellou, O., Cowan, F. M., Hajnal, J. V., Edwards, A. D., and Rutherford, M. A. (2003). Diffusionweighted imaging of the brain in preterm infants with focal and diffuse white matter abnormality. Neoreviews 112,1 .

Crespi, B. J., and Thiselton, D. L. (2011). Comparative immunogenetics of autism and schizophrenia. Genes Brain Behav. 10, 689-701.

Currenti, S. A. (2010). Understanding and determining the etiology of autism. Cell. Mol. Neurobiol. 30 161-171.

Dahlgren, J., Samuelsson, A. M., Jansson, T., and Holmang, A. (2006). Interleukin- 6 in the maternal circulation reaches the rat fetus in midgestation. Pediatr. Res. 60, 147-151.

Darland, D. C., Cain, J. T., Berosik, M. A., Saint-Geniez, M., Odens, P. W., Schaubhut, G. J., Frisch, S., Stemmer-Rachamimov, A., Darland, T., and D'Amore, P. A. (2011). Vascular endothelial growth factor (VEGF) isoform regulation of early forebrain development. Dev. Biol. 358, 9-22.

Dean, C., and Dresbach, T. (2006). Neuroligins and neurexins: linking cell adhesion, synapse formation and cognitive function. Trends Neurosci. 29, 21-29.

Degani, S. (2009). Evaluation of fetal cerebrovascular circulation and brain development: the role of ultrasound and Doppler. Semin. Perinatol. 33, 259-269.

Desai, A. R., and McConnell, S. K. (2000). Progressive restriction in fate potential by neural progenitors during cerebral cortical development. Development 127, 2863-2872. 
Deverman, B. E., and Patterson, P. H. (2009). Cytokines and CNS development. Neuron 64, 61-78.

Dickson, P., Aldred, A., Marley, P., Bannister, D., and Schreiber, G. (1986). Rat choroid plexus specializes in the synthesis and the secretion of transthyretin (prealbumin). Regulation of transthyretin synthesis in choroid plexus is independent from that in liver. J. Biol. Chem. 261, 3475.

Dobrogowska, D. H., and Vorbrodt, A. W. (1999). Quantitative immunocytochemical study of blood-brain barrier glucose transporter (GLUT1) in four regions of mouse brain. J. Histochem. Cytochem. 47, 1021-1030.

Duncan, J. R., Cock, M. L., Suzuki, K., Scheerlinck, J. P., Harding, R., and Rees, S. M. (2006). Chronic endotoxin exposure causes brain injury in the ovine fetus in the absence of hypoxemia. J. Soc. Gynecol. Investig. 13, 87-96.

Durand, C. M., Betancur, C., Boeckers, T. M., Bockmann, J., Chaste, P., Fauchereau, F., Nygren, G., Rastam, M., Gillberg, I. C., Anckarsater, H., Sponheim, E., Goubran-Botros, H., Delorme, R., Chabane, N., MourenSimeoni, M. C., de Mas, P., Bieth, E., Roge, B., Heron, D., Burglen, L., Gillberg, C., Leboyer, M., and Bourgeron, T. (2007). Mutations in the gene encoding the synaptic scaffolding protein shank3 are associated with autism spectrum disorders. Nat. Genet. 39, 25-27.

Dziegielewska, K. M., Ek, J., Habgood, M. D., and Saunders, N. R. (2001). Development of the choroid plexus. Microsc. Res. Tech. 52, 5-20.

Dziegielewska, K. M., Evans, C. A., Lai, P. C., Lorscheider, F. L., Malinowska, D. H., Mollgard, K., and Saunders, N. R. (1981). Proteins in cerebrospinal fluid and plasma of fetal rats during development. Dev. Biol. 83, 193-200.

Earle, K. L., and Mitrofanis, J. (1997). Identification of transient microglial cell colonies in the forebrain white matter of developing rats. J. Comp. Neurol. 387, 371-384.

Ek, C. J., Dziegielewska, K. M., Stolp, H., and Saunders, N. R. (2006). Functional effectiveness of the bloodbrain barrier to small water-soluble molecules in developing and adult opossum (Monodelphis domestica). J. Comp. Neurol. 496, 13-26.

Ek, C. J., Habgood, M. D., Dziegielewska, K. M., Potter, A., and Saunders, N. R. (2001). Permeability and route of entry for lipid-insoluble molecules across brain barriers in developing Monodelphis domestica. J. Physiol. 536, 841-853.

Ek, C. J., Habgood, M. D., Dziegielewska, K. M., and Saunders, N. R. (2003). Structural characteristics and barrier properties of the choroid plexuses in developing brain of the opossum (Monodelphis domestica). J. Comp. Neurol. 460, 451-464.

Ek, C. J., Wong, A., Liddelow, S. A., Johansson, P. A., Dziegielewska, K. M., and Saunders, N. R. (2010). Efflux mechanisms at the developing brain barriers: ABC-transporters in the fetal and postnatal rat. Toxicol. Lett. 197, 51-59.

Eklind, S., Mallard, C., Arvidsson, P., and Hagberg, H. (2005). Lipopolysaccharide induces both a primary and a secondary phase of sensitization in the developing rat brain. Pediatr. Res. 58, 112-116.

Eklind, S., Mallard, C., Leverin, A. L., Gilland, E., Blomgren, K., Mattsby-Baltzer, I., and Hagberg, H. (2001). Bacterial endotoxin sensitizes the immature brain to hypoxicischaemic injury. Eur. J. Neurosci. 13, 1101-1106.

Ellman, L. M., and Susser, E. S. (2009). The promise of epidemiologic studies: neuroimmune mechanisms in the etiologies of brain disorders. Neuron 64, 25-27.

Elovitz, M. A., Brown, A. G., Breen, K. Anton, L., Maubert, M., and Burd, I. (2011). Intrauterine inflammation, insufficient to induce parturition, still evokes fetal and neonatal brain injury. Int. J. Dev. Neurosci. 29, 663-671.

Entringer, S., Buss, C., and Wadhwa, P. D. (2010). Prenatal stress and developmental programming of human health and disease risk: concepts and integration of empirical findings. Curr. Opin. Endocrinol. Diabetes Obes. 17, 507-516.

Farkas, L. M., and Huttner, W. B. (2008). The cell biology of neural stem and progenitor cells and its significance for their proliferation versus differentiation during mammalian brain development. Curr. Opin. Cell Biol. 20, 707-715.

Fatemi, S. H., Reutiman, T. J., Folsom, T. D., Huang, H., Oishi, K., Mori, S., Smee, D. F., Pearce, D. A., Winter, C., Sohr, R., and Juckel, G. (2008). Maternal infection leads to abnormal gene regulation and brain atrophy in mouse offspring: implications for genesis of neurodevelopmental disorders. Schizophr. Res. 99, 56-70.

Feleder, C., Tseng, K. Y., Calhoon, G. G., and O'Donnell, P. (2010). Neonatal intrahippocampal immune challenge alters dopamine modulation of prefrontal cortical interneurons in adult rats. Biol. Psychiatry 67, 386-392.

Fietz, S. A., and Huttner, W. B. (2011). Cortical progenitor expansion, self-renewal and neurogenesis-a polarized perspective. Curr. Opin. Neurobiol. 21, 23-35.

Fishell, G., and Rudy, B. (2011). Mechanisms of inhibition within the telencephalon: "where the wild things are”. Annu. Rev. Neurosci. 34 535-567.

Flames, N., Long, J. E., Garratt, A. N., Fischer, T. M., Gassmann, M., Birchmeier, C., Lai, C., Rubenstein, J. L., and Marin, O. (2004). Short- and long-range attraction of cortical gabaergic interneurons by neuregulin-1. Neuron 44, 251-261.

Flames, N. and Marín, O. (2005). Developmental mechanisms underlying the generation of cortical interneuron diversity. Neuron 46, 377-381.

Fletcher, S., Thomas, T., Schreiber, G., Heinrich, P. C., and Yeoh, G. C. (1988). The development of rat alpha 2-macroglobulin. Studies in vivo and in cultured fetal rat hepatocytes. Eur. J. Biochem. 171, 703-709.

Fukui, Y., and Sakata-Haga, H. (2009). Intrauterine environment-genome interaction and children's development (1): ethanol: a teratogen in developing brain. J. Toxicol. Sci. 34(Suppl. 2), SP273-SP278.

Fukumitsu, H., Ohtsuka, M., Murai, R., Nakamura, H., Itoh, K., and Furukawa, S. (2006). Brain-derived neurotrophic factor participates in determination of neuronal laminar fate in the developing mouse cerebral cortex. J. Neurosci. 26, 13218-13230.

Furuta, A., and Martin, L. J. (1999). Laminar segregation of the cortical plate during corticogenesis is accompanied by changes in glutamate receptor expression. J. Neurobiol. 39, 67-80.

Gaengel, K., Genove, G., Armulik, A., and Betsholtz, C. (2009). Endothelial-mural cell signaling in vascular development and angiogenesis. Arterioscler. Thromb. Vasc. Biol. 29, 630-638.

Gal, J. S., Morozov, Y. M., Ayoub, A. E., Chatterjee, M., Rakic, P., and Haydar, T. F. (2006). Molecular and morphological heterogeneity of neural precursors in the mouse neocortical proliferative zones. J. Neurosci. 26, 1045-1056.

Gato, A., and Desmond, M. E. (2009). Why the embryo still matters: CSF and the neuroepithelium as interdependent regulators of embryonic brain growth, morphogenesis and histiogenesis. Dev. Biol. 327, 263-272.

Gejman, P. V., Sanders, A. R., and Kendler, K. S. (2011). Genetics of schizophrenia: new findings and challenges. Annu. Rev. Genomics Hum. Genet. 12, 121-144.

Genetta, T., Lee, B. H., and Sola, A. (2007). Low doses of ethanol and hypoxia administered together act synergistically to promote the death of cortical neurons. J. Neurosci. Res. 85, 131-138.

Ginhoux, F., Greter, M., Leboeuf, M., Nandi, S., See, P., Gokhan, S., Mehler, M. F., Conway, S. J., Ng, L. G., Stanley, E. R., Samokhvalov, I. M., and Merad, M. (2010). Fate mapping analysis reveals that adult microglia derive from primitive macrophages. Science 330, 841-845.

Girard, S., Tremblay, L., Lepage, M., and Sebire, G. (2010). IL-1 receptor antagonist protects against placental and neurodevelopmental defects induced by maternal inflammation. J. Immunol. 184, 3997-4005.

Glessner, J. T., Wang, K., Cai, G., Korvatska, O., Kim, C. E., Wood, S., Zhang, H., Estes, A., Brune, C. W. Bradfield, J. P., Imielinski, M., Frackelton, E. C., Reichert, J., Crawford, E. L., Munson, J., Sleiman, P. M., Chiavacci, R., Annaiah, K., Thomas, K., Hou, C., Glaberson, W., Flory, J., Otieno, F., Garris, M., Soorya, L., Klei, L., Piven, J., Meyer, K. J., Anagnostou, E., Sakurai, T., Game, R. M., Rudd, D. S., Zurawiecki, D., McDougle, C. J., Davis, L. K., Miller, J., Posey, D. J., Michaels, S., Kolevzon, A., Silverman, J. M., Bernier, R., Levy, S. E., Schultz, R. T., Dawson, G., Owley, T., McMahon, W. M., Wassink, T. H., Sweeney, J. A., Nurnberger, J. I., Coon, H., Sutcliffe, J. S., Minshew, N. J., Grant, S. F., Bucan, M., Cook, E. H., Buxbaum, J. D., Devlin, B., Schellenberg, G. D., and Hakonarson, H. (2009). Autism genome-wide copy number variation reveals ubiquitin and neuronal genes. Nature 459, 569-573.

Gluckman, P. D., Hanson, M. A., and Low, F. M. (2011). The role of developmental plasticity and epigenetics in human health. Birth Defects Res. C Embryo Today 93, 12-18.

Golan, H. M., Lev, V., Hallak, M., Sorokin, Y., and Huleihel, M. (2005). Specific neurodevelopmental damage in mice offspring following maternal inflammation during 
pregnancy. Neuropharmacology 48, 903-917.

Guerri, C. (2002). Mechanisms involved in central nervous system dysfunctions induced by prenatal ethanol exposure. Neurotox. Res. 4, 327-335.

Guillemot, F., Molnar, Z., Tarabykin, V., and Stoykova, A. (2006). Molecular mechanisms of cortical differentiation. Eur. J. Neurosci. 23, 857-868.

Gunn, A. J., and Bennet, L. (2009). Fetal hypoxia insults and patterns of brain injury: insights from animal models. Clin. Perinatol. 36, 579-593.

Habgood, M. D., Sedgwick, J. E., Dziegielewska, K. M., and Saunders, N. R. (1992). A developmentally regulated blood-cerebrospinal fluid transfer mechanism for albumin in immature rats. J. Physiol. 456, 181-192.

Hagberg, H., Peebles, D., and Mallard, C. (2002). Models of white matter injury: comparison of infectious, hypoxic-ischemic, and excitotoxic insults. Ment. Retard Dev. Disabil. Res. Rev. 8, 30-38.

Hanahan, D. (1997). Signaling vascular morphogenesis and maintenance. Science 277, 48-50.

Hansen, D. V., Lui, J. H., Parker, P. R., and Kriegstein, A. R. (2010). Neurogenic radial glia in the outer subventricular zone of human neocortex. Nature 464, 554-561.

Harris, A., and Seckl, J. (2011). Glucocorticoids, prenatal stress and the programming of disease. Horm. Behav. 59, 279-289.

Harrison, P. J., and Weinberger, D. R. (2005). Schizophrenia genes, gene expression, and neuropathology: on the matter of their convergence. Mol. Psychiatry 10, 40-68; image 5.

Hartfuss, E., Galli, R., Heins, N., and Gotz, M. (2001). Characterization of CNS precursor subtypes and radial glia. Dev. Biol. 229, 15-30.

Harvey, J. A. (2004). Cocaine effects on the developing brain: current status. Neurosci. Biobehav. Rev. 27, 751-764.

Hawdon, J. M. (2011). Babies born after diabetes in pregnancy: what are the short- and long-term risks and how can we minimise them? Best Pract. Res. Clin. Obstet. Gynaecol. 25, 91-104.

Haydon, P. G., and Carmignoto, G. (2006). Astrocyte control of synaptic transmission and neurovascular coupling. Physiol. Rev. 86, 1009-1031.

Haynes, B. F., Singer, K. H., Denning, S. M., and Martin, M. E. (1988). Analysis of expression of CD2, $\mathrm{CD} 3$, and $\mathrm{T}$ cell antigen receptor molecules during early human fetal thymic development. J. Immunol. 141, 3776-3784.

Hernandez-Miranda, L. R., Parnavelas, J. G., and Chiara, F. (2010). Molecules and mechanisms involved in the generation and migration of cortical interneurons. ASN Neuro 2, e00031.

Hevner, R. F., Hodge, R. D., Daza, R. A., and Englund, C. (2006). Transcription factors in glutamatergic neurogenesis: conserved programs in neocortex, cerebellum, and adult hippocampus. Neurosci. Res. 55, 223-233.

Hoerder-Suabedissen, A., Paulsen, O., and Molnar, Z. (2008). Thalamocortical maturation in mice is influenced by body weight. J. Comp. Neurol. 511, 415-420.

Hoerder-Suabedissen, A., Wang, W. Z., Lee, S., Davies, K. E., Goffinet, A. M., Rakic, S., Parnavelas, J., Reim, K., Nicolic, M., Paulsen, O., and Molnar, Z. (2009). Novel markers reveal subpopulations of subplate neurons in the murine cerebral cortex. Cereb. Cortex 19, 1738-1750.

Holt, P. G., and Jones, C. A. (2000). The development of the immune system during pregnancy and early life. Allergy 55, 688-697.

Hristova, M., Cuthill, D., Zbarsky, V., Acosta-Saltos, A., Wallace, A., Blight, K., Buckley, S. M., Peebles, D., Heuer, H., Waddington, S. N., and Raivich, G. (2010). Activation and deactivation of periventricular white matter phagocytes during postnatal mouse development. Glia 58, 11-28.

Hsiao, E. Y., and Patterson, P. H. (2011). Activation of the maternal immune system induces endocrine changes in the placenta via IL-6. Brain Behav. Immun. 25, 604-615.

Huppertz, B., Burton, G., Cross, J. C., and Kingdom, J. C. (2006). Placental morphology: from molecule to mother - a dedication to Peter Kaufmann - a review. Placenta 27(Suppl. A), S3-S8.

Hutton, L. C., Castillo-Melendez, M., Smythe, G. A., and Walker, D. W. (2008). Microglial activation, macrophage infiltration, and evidence of cell death in the fetal brain after uteroplacental administration of lipopolysaccharide in sheep in late gestation. Am. J. Obstet. Gynecol. 198, 117 e111-e111.

Hynes, M. A., Brooks, P. J., Van Wyk, J. J., and Lund, P. K. (1988). Insulin-like growth factor II messenger ribonucleic acids are synthesized in the choroid plexus of the rat brain. Mol. Endocrinol. 2, 47.
Ibi, D., Nagai, T., Koike, H., Kitahara, Y., Mizoguchi, H., Niwa, M. Jaaro-Peled, H., Nitta, A., Yoneda, Y., Nabeshima, T., Sawa, A., and Yamada, K. (2010). Combined effect of neonatal immune activation and mutant discl on phenotypic changes in adulthood. Behav. Brain Res. 206 32-37.

Impey, L., Greenwood, C., Sheil, O., Macquillan, K., Reynolds, M., and Redman, C. (2001). The relation between pre-eclampsia at term and neonatal encephalopathy. Arch. Dis. Child. Fetal Neonatal Ed. 85, F170F172.

Jacobsen, C. T., and Miller, R. H. (2003). Control of astrocyte migration in the developing cerebral cortex. Dev. Neurosci. 25, 207-216.

Javaherian, A., and Kriegstein, A. (2009). A stem cell niche for intermediate progenitor cells of the embryonic cortex. Cereb. Cortex 19(Suppl. 1) i70-i77.

Jenkins, T. A., Harte, M. K., Stenson, G., and Reynolds, G. P. (2009). Neonatal lipopolysaccharide induces pathological changes in parvalbumin immunoreactivity in the hippocampus of the rat. Behav. Brain Res. 205, 355-359.

Jimenez, D., Lopez-Mascaraque, L. M. Valverde, F., and De Carlos, J. A. (2002). Tangential migration in neocortical development. Dev. Biol. 244 155-169.

Johansson, P. A., Dziegielewska, K. M., Ek, C. J., Habgood, M. D., Liddelow, S. A., Potter, A. M., Stolp, H. B., and Saunders, N. R. (2006) Blood-CSF barrier function in the rat embryo. Eur. J. Neurosci. 24 65-76.

Johansson, P. A., Dziegielewska, K. M., Ek, C. J., Habgood, M. D., Mollgard, K., Potter, A., Schuliga, M., and Saunders, N. R. (2005). Aquaporin1 in the choroid plexuses of developing mammalian brain. Cell Tissue Res. 322, 353-364.

Johansson, P. A., Dziegielewska, K. M. Liddelow, S. A., and Saunders, N. R. (2008). The blood-CSF barrier explained: when development is not immaturity. Bioessays 30, 237-248.

Jones, C. A., Holloway, J. A., and Warner, J. O. (2002). Fetal immune responsiveness and routes of allergic sensitization. Pediatr. Allergy Immunol. 13(Suppl. 15), 19-22.

Jones, E. G. (2009). The origins of cortical interneurons: mouse versus monkey and human. Cereb. Cortex 19, 1953-1956.

Juliandi, B., Abematsu, M., and Nakashima, K. (2010). Epigenetic regulation in neural stem cell differentiation. Dev. Growth Differ. 52, 493-504.

Kamiya, A., Kubo, K., Tomoda, T., Takaki, M., Youn, R., Ozeki, Y., Sawamura, N., Park, U., Kudo, C., Okawa, M., Ross, C. A., Hatten, M. E., Nakajima, K., and Sawa, A. (2005). A schizophrenia-associated mutation of discl perturbs cerebral cortex development. Nat. Cell Biol. 7, 1167-1178.

Kanold, P. O., and Luhmann, H. J. (2010). The subplate and early cortical circuits. Annu. Rev. Neurosci. 33, 23-48.

Kaukola, T., Kapellou, O., Laroche, S., Counsell, S. J., Dyet, L. E., Allsop, J. M., and Edwards, A. D (2009). Severity of perinatal illness and cerebral cortical growth in preterm infants. Acta Paediatr. 98, 990-995.

Keimpema, E., Mackie, K., and Harkany, T. (2011). Molecular model of cannabis sensitivity in developing neuronal circuits. Trends Pharmacol. Sci. 32, 551-561.

Kessaris, N., Fogarty, M., Iannarelli, P., Grist, M., Wegner, M., and Richardson, W. D. (2006). Competing waves of oligodendrocytes in the forebrain and postnatal elimination of an embryonic lineage. Nat. Neurosci. 9, 173-179.

Keverne, E. B. (2010). Epigenetically regulated imprinted genes and foetal programming. Neurotox. Res. 18, 386-392.

Kim, H. G., Kishikawa, S., Higgins, A. W., Seong, I. S., Donovan, D. J., Shen, Y., Lally, E., Weiss, L. A., Najm, J., Kutsche, K., Descartes, M., Holt, L., Braddock, S., Troxell, R., Kaplan, L., Volkmar, F., Klin, A., Tsatsanis, K., Harris, D. J., Noens, I., Pauls, D. L., Daly, M. J., MacDonald, M. E., Morton, C. C., Quade, B. J., and Gusella, J. F. (2008). Disruption of neurexin 1 associated with autism spectrum disorder. Am. J. Hum. Genet. 82, 199-207.

Kitraki, E., Alexis, M. N., Papalopoulou, M., and Stylianopoulou, F. (1996). Glucocorticoid receptor gene expression in the embryonic rat brain. Neuroendocrinology 63, 305-317.

Kitraki, E., Kittas, C., and Stylianopoulou, F. (1997). Glucocorticoid receptor gene expression during rat embryogenesis. An in situ hybridization study. Differentiation 62, 21-31.

Konno, D., Shioi, G., Shitamukai, A., Mori, A., Kiyonari, H., Miyata, T., and Matsuzaki, F. (2008). Neuroepithelial progenitors undergo LGN-dependent planar divisions to maintain self-renewability during 
mammalian neurogenesis. Nat. Cell Biol. 10, 93-101.

Kostovic, I., and Rakic, P. (1990). Developmental history of the transient subplate zone in the visual and somatosensory cortex of the macaque monkey and human brain. J. Comp. Neurol. 297, 441-470.

Kowalczyk, T., Pontious, A., Englund, C., Daza, R. A., Bedogni, F., Hodge, R., Attardo, A., Bell, C., Huttner, W. B., and Hevner, R. F. (2009). Intermediate neuronal progenitors (basal progenitors) produce pyramidalprojection neurons for all layers of cerebral cortex. Cereb. Cortex 19, 2439-2450.

Kucukdereli, H., Allen, N. J., Lee, A. T., Feng, A., Ozlu, M. I., Conatser, L. M., Chakraborty, C., Workman, G., Weaver, M., Sage, E. H., Barres, B. A., and Eroglu, C. (2011). Control of excitatory CNS synaptogenesis by astrocytesecreted proteins Hevin and SPARC. Proc. Natl. Acad. Sci. U.S.A. 108, E440-E449.

Langseth, A. J., Munji, R. N., Choe, Y., Huynh, T., Pozniak, C. D., and Pleasure, S. J. (2010). Wnts influence the timing and efficiency of oligodendrocyte precursor cell generation in the telencephalon. J. Neurosci. 30, 13367-13372.

Larouche, A., Roy, M., Kadhim, H., Tsanaclis, A. M., Fortin, D., and Sebire, G. (2005). Neuronal injuries induced by perinatal hypoxicischemic insults are potentiated by prenatal exposure to lipopolysaccharide: animal model for perinatally acquired encephalopathy. Dev. Neurosci. 27, 134-142.

Larrivee, B., Freitas, C., Suchting, S., Brunet, I., and Eichmann, A. (2009). Guidance of vascular development: lessons from the nervous system. Circ. Res. 104, 428-441.

Lathia, J. D., Okun, E., Tang, S. C., Griffioen, K., Cheng, A., Mughal, M. R., Laryea, G., Selvaraj, P. K., Ffrench-Constant, C., Magnus, T., Arumugam, T. V., and Mattson, M. P. (2008). Toll-like receptor 3 is a negative regulator of embryonic neural progenitor cell proliferation. J. Neurosci. 28, 13978-13984.

Laumonnier, F., Bonnet-Brilhault, F., Gomot, M., Blanc, R., David, A., Moizard, M. P., Raynaud, M., Ronce, N., Lemonnier, E., Calvas, P., Laudier, B., Chelly, J., Fryns, J. P., Ropers, H. H., Hamel, B. C., Andres, C., Barthelemy, C., Moraine, C., and Briault, S. (2004). X-linked mental retardation and autism are associated with a mutation in the nlgn4 gene, a member of the neuroligin family. Am. J. Hum. Genet. 74, 552557.

Lavdas, A. A., Grigoriou, M., Pachnis, V., and Parnavelas, J. G. (1999). The medial ganglionic eminence gives rise to a population of early neurons in the developing cerebral cortex. $J$. Neurosci. 19, 7881-7888.

Lee, C. T., Chen, J., Worden, L. T., and Freed, W. J. (2011). Cocaine causes deficits in radial migration and alters the distribution of glutamate and GABA neurons in the developing rat cerebral cortex. Synapse 65, 21-34.

Lehtinen, M. K., Zappaterra, M. W., Chen, X., Yang, Y. J., Hill, A. D., Lun, M., Maynard, T., Gonzalez, D., Kim, S., Ye, P., D’Ercole, A. J., Wong, E. T., Lamantia, A. S., and Walsh, C. A. (2011). The cerebrospinal fluid provides a proliferative niche for neural progenitor cells. Neuron 69, 893-905.

Letinic, K., and Rakic, P. (2001). Telencephalic origin of human thalamic gabaergic neurons. Nat. Neurosci. 4, 931-936.

Letinic, K., Zoncu, R., and Rakic, P. (2002). Origin of gabaergic neurons in the human neocortex. Nature 417, 645-649.

Leviton, A., Hecht, J. L., Allred, E. N., Yamamoto, H., Fichorova, R. N., and Dammann, O. (2011). Persistence after birth of systemic inflammation associated with umbilical cord inflammation. J. Reprod. Immunol. 90, 235-243.

Levitt, P. (2005). Disruption of interneuron development. Epilepsia 46(Suppl. 7), 22-28.

Lewis, D. A., Hashimoto, T., and Volk, D. W. (2005). Cortical inhibitory neurons and schizophrenia. Nat. Rev. Neurosci. 6, 312-324.

Liddelow, S. A., Dziegielewska, K. M., Ek, C. J., Johansson, P. A., Potter, A. M., and Saunders, N. R. (2009). Cellular transfer of macromolecules across the developing choroid plexus of Monodelphis domestica. Eur. J. Neurosci. 29, 253-266.

Liddelow, S. A., Dziegielewska, K. M., Vandeberg, J. L., Noor, N. M., Potter, A. M., and Saunders, N. R. (2011). Modification of protein transfer across blood/cerebrospinal fluid barrier in response to altered plasma protein composition during development. Eur. J. Neurosci. 33, 391-400.

Liebner, S., Czupalla, C. J., and Wolburg, H. (2011). Current concepts of blood-brain barrier development. Int. J. Dev. Biol. 55, 467-476.

Lindahl, P., Johansson, B. R., Leveen, P., and Betsholtz, C. (1997). Pericyte loss and microaneurysm formation in PDGF-B-deficient mice. Science 277, 242-245.

Ling, Z., Gayle, D. A., Ma, S. Y., Lipton, J. W., Tong, C. W., Hong, J. S., and Carvey, P. M. (2002). In utero bacterial endotoxin exposure causes loss of tyrosine hydroxylase neurons in the postnatal rat midbrain. Mov. Disord. 17, 116-124.

Ling, Z. D., Chang, Q., Lipton, J. W., Tong, C. W., Landers, T. M., and Carvey, P. M. (2004). Combined toxicity of prenatal bacterial endotoxin exposure and postnatal 6-hydroxydopamine in the adult rat midbrain. Neuroscience 124, 619-628.

Liu, J., and Casaccia, P. (2010). Epigenetic regulation of oligodendrocyte identity. Trends Neurosci. 33, 193-201.

Lok, J., Gupta, P., Guo, S., Kim, W. J., Whalen, M. J., Van Leyen, K., and Lo, E. H. (2007). Cell-cell signaling in the neurovascular unit. Neurochem. Res. 32, 2032-2045.

Lou, H. C., Rosa, P., Pryds, O., Karrebaek, H., Lunding, J., Cumming, P., and Gjedde, A. (2004). Adhd: increased dopamine receptor availability linked to attention deficit and low neonatal cerebral blood flow. Dev. Med. Child Neurol. 46, 179-183.

Lui, J. H., Hansen, D. V., and Kriegstein, A. R. (2011). Development and evolution of the human neocortex. Cell 146, 18-36.

Lukaszewicz, A., Savatier, P., Cortay, V. Kennedy, H., and Dehay, C. (2002). Contrasting effects of basic fibroblast growth factor and neurotrophin 3 on cell cycle kinetics of mouse cortical stem cells. J. Neurosci. 22, 6610-6622.

Mahmood, S., Ahmad, W., and Hassan, M. J. (2011). Autosomal Recessive Primary Microcephaly (MCPH): clinical manifestations, genetic heterogeneity and mutation continuum. Orphanet. J. Rare Dis. 6, 39 .

Malatesta, P., Hartfuss, E., and Gotz, M. (2000). Isolation of radial glial cells by fluorescent-activated cell sorting reveals a neuronal lineage. Development 127, 5253-5263.

Marín, O. (2012). Interneuron dysfunction in psychiatric disorders. Nat. Rev. Neurosci. 13, 107-120.

Marin-Padilla, M. (1971). Early prenatal ontogenesis of the cerebral cortex (neocortex) of the cat (Felis domestica). A Golgi study. I. The primordial neocortical organization. Z. Anat. Entwicklungsgesch 134, 117-145.
Marques, F., Sousa, J. C., Coppola, G., Geschwind, D. H., Sousa, N., Palha, J. A., and Correia-Neves, M. (2009). The choroid plexus response to a repeated peripheral inflammatory stimulus. BMC Neurosci. 10, 135. doi:10.1186/1471-2202-10-135

Marshall, C. R., Noor, A., Vincent, J. B., Lionel, A. C., Feuk, L., Skaug, J., Shago, M., Moessner, R., Pinto, D., Ren, Y., Thiruvahindrapduram, B., Fiebig, A., Schreiber, S., Friedman, J., Ketelaars, C. E., Vos, Y. J., Ficicioglu, C., Kirkpatrick, S., Nicolson, R., Sloman, L., Summers, A., Gibbons, C. A., Teebi, A., Chitayat, D., Weksberg, R., Thompson, A., Vardy, C., Crosbie, V., Luscombe, S., Baatjes, R., Zwaigenbaum, L., Roberts, W., Fernandez, B., Szatmari, P., and Scherer, S. W. (2008). Structural variation of chromosomes in autism spectrum disorder. Am. J. Hum. Genet. 82, 477-488.

Martin, C., Bueno, D., Alonso, M. I., Moro, J. A., Callejo, S., Parada, C., Martin, P., Carnicero, E., and Gato, A. (2006). FGF2 plays a key role in embryonic cerebrospinal fluid trophic properties over chick embryo neuroepithelial stem cells. Dev. Biol. 297, 402-416.

Martínez-Cerdeño, V., Noctor, S. C., and Kriegstein, A. R. (2006). Estradiol stimulates progenitor cell division in the ventricular and subventricular zones of the embryonic neocortex. Eur. J. Neurosci. 24, 3475-3488.

Maynard, T. M., Sikich, L., Lieberman, J. A., and Lamantia, A. S. (2001). Neural development, cell-cell signaling, and the "two-hit" hypothesis of schizophrenia. Schizophr. Bull. 27, 457-476.

McCarthy, D. M., Zhang, X., Darnell, S. B., Sangrey, G. R., Yanagawa, Y., Sadri-Vakili, G., and Bhide, P. G. (2011). Cocaine alters BDNF expression and neuronal migration in the embryonic mouse forebrain. $\mathrm{J}$. Neurosci. 31, 13400-13411.

McClure, M. M., Riddle, A., Manese, M., Luo, N. L., Rorvik, D. A., Kelly, K. A., Barlow, C. H., Kelly, J. J., Vinecore, K., Roberts, C. T., Hohimer, A. R., and Back, S. A. (2008). Cerebral blood flow heterogeneity in preterm sheep: lack of physiologic support for vascular boundary zones in fetal cerebral white matter. J. Cereb. Blood Flow Metab. 28, 995-1008.

McKercher, S. R., Torbett, B. E., Anderson, K. L., Henkel, G. W., Vestal, D. J., Baribault, H., Klemsz, M., Feeney, A. J., Wu, G. E., Paige, C. J., and Maki, R. A. (1996). Targeted disruption 
of the PU.1 gene results in multiple hematopoietic abnormalities. EMBO J. 15, 5647-5658.

McQuillen, P. S., Sheldon, R. A., Shatz, C. J., and Ferriero, D. M. (2003). Selective vulnerability of subplate neurons after early neonatal hypoxia-ischemia. J. Neurosci. 23, 3308-3315.

Meaney, M. J., Szyf, M., and Seckl, J. R. (2007). Epigenetic mechanisms of perinatal programming of hypothalamic-pituitary-adrenal function and health. Trends. Mol. Med. 13, 269-277.

Medzhitov, R. (2007). Recognition of microorganisms and activation of the immune response. Nature 449, 819-826.

Melchers, F. (1979). Murine embryonic B lymphocyte development in the placenta. Nature 277, 219-221.

Métin, C., Vallee, R. B., Rakic, P., and Bhide, P. G. (2008). Modes and mishaps of neuronal migration in the mammalian brain. J. Neurosci. 28, 11746-11752.

Meyer, U., and Feldon, J. (2009). Neural basis of psychosis-related behaviour in the infection model of schizophrenia. Behav. Brain Res. 204, 322-334.

Meyer, U., Feldon, J., Schedlowski, M., and Yee, B. K. (2005). Towards an immuno-precipitated neurodevelopmental animal model of schizophrenia. Neurosci. Biobehav. Rev. 29, 913-947.

Meyer, U., Schwendener, S., Feldon, J., and Yee, B. K. (2006). Prenatal and postnatal maternal contributions in the infection model of schizophrenia. Exp. Brain Res. 173, 243-257.

Michaelson, M. D., Bieri, P. L., Mehler, M. F., Xu, H., Arezzo, J. C., Pollard, J. W., and Kessler, J. A. (1996). CSF-1 deficiency in mice results in abnormal brain development. Development 122, 2661-2672.

Michaelsson, J., Mold, J. E., McCune, J. M., and Nixon, D. F. (2006). Regulation of $\mathrm{T}$ cell responses in the developing human fetus. J. Immunol. 176, 5741-5748.

Millar, J. K., Wilson-Annan, J. C., Anderson, S., Christie, S., Taylor, M. S., Semple, C. A., Devon, R. S., St Clair, D. M., Muir, W. J., Blackwood, D. H., and Porteous, D. J. (2000). Disruption of two novel genes by a translocation co-segregating with schizophrenia. Hum. Mol. Genet. 9, 1415-1423.

Molnár, Z., and Blakemore, C. (1995). How do thalamic axons find their way to the cortex? Trends Neurosci. 18, 389-397.
Molne, M., Studer, L., Tabar, V., Ting, Y. T., Eiden, M. V., and McKay, R. D. (2000). Early cortical precursors do not undergo LIF-mediated astrocytic differentiation. J. Neurosci. Res. 59, 301-311.

Molyneaux, B. J., Arlotta, P., Menezes, J. R., and Macklis, J. D. (2007). Neuronal subtype specification in the cerebral cortex. Nat. Rev. Neurosci. 8, 427-437.

Müller, C. M., and Best, J. (1989). Ocular dominance plasticity in adult cat visual cortex after transplantation of cultured astrocytes. Nature 342, 427-430.

Murphy, V. E., Smith, R., Giles, W. B., and Clifton, V. L. (2006). Endocrine regulation of human fetal growth: the role of the mother, placenta, and fetus. Endocr. Rev. 27, 141-169.

Neal, A. P., Stansfield, K. H., Worley, P. F., Thompson, R. E., and Guilarte, T. R. (2010). Lead exposure during synaptogenesis alters vesicular proteins and impairs vesicular release: potential role of NMDA receptordependent BDNF signaling. Toxicol. Sci. 116, 249-263.

Neerhof, M. G., and Thaete, L. G. (2008). The fetal response to chronic placental insufficiency. Semin. Perinatol. 32, 201-205.

Nery, S., Fishell, G., and Corbin, J. G. (2002). The caudal ganglionic eminence is a source of distinct cortical and subcortical cell populations. Nat. Neurosci. 5, 1279-1287.

Neuwelt, E. A., Bauer, B., Fahlke, C., Fricker, G., Iadecola, C., Janigro, D., Leybaert, L., Molnar, Z., O’Donnell, M. E., Povlishock, J. T., Saunders, N. R., Sharp, F., Stanimirovic, D., Watts, R. J., and Drewes, L. R. (2011). Engaging neuroscience to advance translational research in brain barrier biology. Nat. Rev. Neurosci. 12, 169-182.

Nguyen, V., and McQuillen, P. S. (2010). AMPA and metabotropic excitoxicity explain subplate neuron vulnerability. Neurobiol. Dis. 37, 195-207.

Nicodemus, K. K., Marenco, S., Batten, A. J., Vakkalanka, R., Egan, M. F., Straub, R. E., and Weinberger, D. R. (2008). Serious obstetric complications interact with hypoxia-regulated/vascularexpression genes to influence schizophrenia risk. Mol. Psychiatry 13, 873-877.

Nie, K., Molnar, Z., and Szele, F. G. (2010). Proliferation but not migration is associated with blood vessels during development of the rostral migratory stream. Dev. Neurosci. 32, 163-172.
Nitta, T., Hata, M., Gotoh, S., Seo, Y., Sasaki, H., Hashimoto, N., Furuse, M., and Tsukita, S. (2003). Sizeselective loosening of the bloodbrain barrier in claudin-5-deficient mice. J. Cell Biol. 161, 653-660.

Noctor, S. C., Martinez-Cerdeno, V. Ivic, L., and Kriegstein, A. R. (2004). Cortical neurons arise in symmetric and asymmetric division zones and migrate through specific phases. Nat. Neurosci. 7, 136-144.

Noebels, J. L. (2003). The biology of epilepsy genes. Annu. Rev. Neurosci. 26, 599-625.

O'Connell, G., Lawrie, S. M., McIntosh, A. M., and Hall, J. (2011). Schizophrenia risk genes: implications for future drug development and discovery. Biochem. Pharmacol. 81, 1367-1373.

Oh, G., and Petronis, A. (2008). Environmental studies of schizophrenia through the prism of epigenetics. Schizophr. Bull. 34, 1122-1129.

Okun, E., Griffioen, K. J., Son, T. G., Lee, J. H., Roberts, N. J., Mughal, M. R., Hutchison, E., Cheng, A., Arumugam, T. V., Lathia, J. D., Van Praag, H., and Mattson, M. P. (2010). TLR2 activation inhibits embryonic neural progenitor cell proliferation. J. Neurochem. 114, 462-474.

Oliver, P. L. (2011). Challenges of analysing gene-environment interactions in mouse models of schizophrenia. ScientificWorldJournal 11, 1411-1420.

O'Shea, T. M., Allred, E. N., Dammann, O., Hirtz, D., Kuban, K. C., Paneth, N., and Leviton, A. (2009). The elgan study of the brain and related disorders in extremely low gestational age newborns. Early Hum. Dev. 85, 719-725.

Orsi, N. M., and Tribe, R. M. (2008). Cytokine networks and the regulation of uterine function in pregnancy and parturition. J. Neuroendocrinol. 20, 462-469.

Paolicelli, R. C., Bolasco, G., Pagani, F., Maggi, L., Scianni, M., Panzanelli, P., Giustetto, M., Ferreira, T. A., Guiducci, E., Dumas, L., Ragozzino, D., and Gross, C. T. (2011). Synaptic pruning by microglia is necessary for normal brain development. Science 333, 1456-1458.

Parker-Athill, E. C., and Tan, J. (2010). Maternal immune activation and autism spectrum disorder: interleukin-6 signaling as a key mechanistic pathway. Neurosignal $18,113-128$.

Parnavelas, J. G. (2000). The origin and migration of cortical neurones: new vistas. Trends Neurosci. 23, 126-131.
Patel, J., Landers, K., Li, H., Mortimer, R. H., and Richard, K. (2011). Thyroid hormones and fetal neurological development. J. Endocrinol. 209, 1-8.

Patterson, P. H. (2009). Immune involvement in schizophrenia and autism: etiology, pathology and animal models. Behav. Brain Res. 204, 313-321.

Paul-Samojedny, M., Kowalczyk, M., Suchanek, R., Owczarek, A., FilaDanilow, A., Szczygiel, A., and Kowalski, J. (2010). Functional polymorphism in the interleukin-6 and interleukin-10 genes in patients with paranoid schizophrenia-a casecontrol study. J. Mol. Neurosci. 42, 112-119.

Pearce, B. D., Valadi, N. M., Po, C. L., and Miller, A. H. (2000). Viral infection of developing GABAergic neurons in a model of hippocampal disinhibition. Neuroreport 11, 2433-2438.

Pearce, W. (2006). Hypoxic regulation of the fetal cerebral circulation. $J$. Appl. Physiol. 100, 731-738.

Peñagarikano, O., Abrahams, B. S., Herman, E. I., Winden, K. D., Gdalyahu, A., Dong, H., Sonnenblick, L. I., Gruver, R., Almajano, J., Bragin, A., Golshani, P., Trachtenberg, J. T., Peles, E., and Geschwind, D. H. (2011). Absence of cntnap2 leads to epilepsy, neuronal migration abnormalities, and core autism-related deficits. Cell 147, 235-246.

Peppiatt, C. M., Howarth, C., Mobbs, P., and Attwell, D. (2006). Bidirectional control of CNS capillary diameter by pericytes. Nature 443, 700-704.

Petanjek, Z., Kostovic, I., and Esclapez, M. (2009). Primate-specific origins and migration of cortical GABAergic neurons. Front. Neuroanat. 3:26. doi:10.3389/neuro.05.026.2009

Peter, C. J., and Akbarian, S. (2011). Balancing histone methylation activities in psychiatric disorders. Trends Mol. Med. 17, 372-379.

Pinto, L., and Götz, M. (2007). Radial glial cell heterogeneity-the source of diverse progeny in the CNS. Prog. Neurobiol. 83, 2-23.

Poulton, C. J., Schot, R., Kia, S. K., Jones, M., Verheijen, F. W., Venselaar, H., De Wit, M. C., De Graaff, E., Bertoli-Avella, A. M., and Mancini, G. M. (2011). Microcephaly with simplified gyration, epilepsy, and infantile diabetes linked to inappropriate apoptosis of neural progenitors. Am. J. Hum. Genet. 89, 265-276.

Prinz, M., and Mildner, A. (2011). Microglia in the CNS: immigrants 
from another world. Glia 59, 177-187.

Quaegebeur, A., Lange, C., and Carmeliet, P. (2011). The neurovascular link in health and disease: molecular mechanisms and therapeutic implications. Neuron 71, 406-424.

Quaegebeur, A., Segura, I., and Carmeliet, P. (2010). Pericytes: blood-brain barrier safeguards against neurodegeneration? Neuron 68, 321-323.

Raikkonen, K., and Pesonen, A. K. (2009). Early life origins of psychological development and mental health. Scand. J. Psychol. 50, 583-591.

Rakic, P., and Sidman, R. L. (1968). Supravital DNA synthesis in the developing human and mouse brain. J. Neuropathol. Exp. Neurol. 27, 246-276.

Redman, C. W., and Sargent, I. L. (2005). Latest advances in understanding preeclampsia. Science 308, 1592-1594.

Rees, S., Harding, R., and Walker, D. (2008). An adverse intrauterine environment: implications for injury and altered development of the brain. Int. J. Dev. Neurosci. 26, 3-11.

Rezaie, P., and Dean, A. (2002). Periventricular leukomalacia, inflammation and white matter lesions within the developing nervous system. Neuropathology 22, 106-132.

Rio, C., Rieff, H. I., Qi, P., Khurana, T. S., and Corfas, G. (1997). Neuregulin and erbb receptors play a critical role in neuronal migration. Neuron 19, 39-50.

Rivera, F. J., Steffenhagen, C., Kremer, D., Kandasamy, M., Sandner, B., Couillard-Despres, S., Weidner, N., Kury, P., and Aigner, L. (2010). Deciphering the oligodendrogenic program of neural progenitors: cell intrinsic and extrinsic regulators. Stem Cells Dev. 19, 595-606.

Rogerson, S. J., and Boeuf, P. (2007). New approaches to pathogenesis of malaria in pregnancy. Parasitology 134, 1883-1893.

Roumier, A., Pascual, O., Bechade, C., Wakselman, S., Poncer, J. C., Real, E., Triller, A., and Bessis, A. (2008). Prenatal activation of microglia induces delayed impairment of glutamatergic synaptic function. PLoS ONE 3, e2595. doi:10.1371/journal.pone.0002595

Rubert, G., Minana, R., Pascual, M., and Guerri, C. (2006). Ethanol exposure during embryogenesis decreases the radial glial progenitorpool and affects the generation of neurons and astrocytes. J. Neurosci. Res. 84, 483-496.

Rujescu, D., Ingason, A., Cichon, S., Pietilainen, O. P., Barnes, M. R., Toulopoulou, T., Picchioni, M., Vassos, E., Ettinger, U., Bramon, E., Murray, R., Ruggeri, M., Tosato, S., Bonetto, C., Steinberg, S., Sigurdsson, E., Sigmundsson, T., Petursson, H., Gylfason, A., Olason, P. I., Hardarsson, G., Jonsdottir, G. A., Gustafsson, O., Fossdal, R., Giegling, I., Moller, H. J., Hartmann, A. M., Hoffmann, P., Crombie, C., Fraser, G., Walker, N., Lonnqvist, J., Suvisaari, J., Tuulio-Henriksson, A., Djurovic, S., Melle, I., Andreassen, O. A., Hansen, T., Werge, T., Kiemeney, L. A., Franke, B., Veltman, J., BuizerVoskamp, J. E., Sabatti, C., Ophoff, R. A., Rietschel, M., Nothen, M. M., Stefansson, K., Peltonen, L., St Clair, D., Stefansson, H., and Collier, D. A. (2009). Disruption of the neurexin 1 gene is associated with schizophrenia. Hum. Mol. Genet. 18, 988-996.

Rymar, V. V., and Sadikot, A. F. (2007). Laminar fate of cortical GABAergic interneurons is dependent on both birthdate and phenotype. J. Comp. Neurol. 501, 369-380.

Sahara, S., and O'Leary, D. D. (2009). Fgf10 regulates transition period of cortical stem cell differentiation to radial glia controlling generation of neurons and basal progenitors. $\mathrm{Neu}$ ron $63,48-62$.

Saunders, N. R., Ek, C. J., Habgood, M. D., and Dziegielewska, K. M. (2008). Barriers in the brain: a renaissance? Trends Neurosci. 31, 279-286.

Schlegelmilch, T., Henke, K., and Peri, F. (2011). Microglia in the developing brain: from immunity to behaviour. Curr. Opin. Neurobiol.21, 5-10.

Schmidt-Kastner, R., van Os, J., Esquivel, G., Steinbusch, H. W., and Rutten, B. P. (2012). An environmental analysis of genes associated with schizophrenia: hypoxia and vascular factors as interacting elements in the neurodevelopmental model. Mol. Psychiatry. doi: 10.1038/mp.2011.183. [Epub ahead of print].

Schoenwolf, G. C., and Larsen, W. J. (2009). Larsen's Human Embryology. Philadelphia: Churchill Livingstone/Elsevier.

Sessa, A., Mao, C. A., Hadjantonakis, A. K., Klein, W. H., and Broccoli, V. (2008). Tbr2 directs conversion of radial glia into basal precursors and guides neuronal amplification by indirect neurogenesis in the developing neocortex. Neuron 60, 56-69.

Shen, Q., Wang, Y., Dimos, J. T., Fasano, C. A., Phoenix, T. N., Lemischka, I. R., Ivanova, N. B., Stifani, S., Morrisey, E. E., and Temple, S. (2006). The timing of cortical neurogenesis is encoded within lineages of individual progenitor cells. Nat. $\mathrm{Neu}$ rosci. 9, 743-751.

Shen, Q., Wang, Y., Kokovay, E., Lin, G., Chuang, S. M., Goderie, S. K., Roysam, B., and Temple, S. (2008). Adult SVZ stem cells lie in a vascular niche: a quantitative analysis of niche cell-cell interactions. Cell Stem Cell 3, 289-300.

Sirimi, N., and Goulis, D. G. (2010). Obesity in pregnancy. Hormones 9 , 299-306.

Smith, S. E., Li, J., Garbett, K., Mirnics, K., and Patterson, P. H. (2007) Maternal immune activation alters fetal brain development through interleukin-6. J. Neurosci. 27, 1069510702.

Solvason, N., and Kearney, J. F. (1992). The human fetal omentum: a site of B cell generation. J. Exp. Med. 175, 397-404.

Southwell, B., Duan, W., Alcorn, D., Brack, C., Richardson, S., Köhrle, J., and Schreiber, G. (1993). Thyroxine transport to the brain: role of protein synthesis by the choroid plexus. Endocrinology 133, 2116.

Steinecke, A., Gampe, C., Valkova, C., Kaether, C., and Bolz, J. (2012). Disrupted-in-schizophrenia 1 (discl) is necessary for the correct migration of cortical interneurons. J. Neurosci. 32, 738-745.

Stefansson, H., Ophoff, R. A., Steinberg, S., Andreassen, O. A., Cichon, S., Rujescu, D., Werge, T., Pietilainen, O. P., Mors, O., Mortensen, P. B., Sigurdsson, E., Gustafsson, O., Nyegaard, M., Tuulio-Henriksson, A., Ingason, A., Hansen, T., Suvisaari, J., Lonnqvist, J., Paunio, T., Borglum, A. D., Hartmann, A., Fink-Jensen, A., Nordentoft, M., Hougaard, D., Norgaard-Pedersen, B., Bottcher, Y., Olesen, J., Breuer, R., Moller, H. J., Giegling, I., Rasmussen, H. B., Timm, S., Mattheisen, M., Bitter, I., Rethelyi, J. M., Magnusdottir, B. B., Sigmundsson, T., Olason, P., Masson, G., Gulcher, J. R., Haraldsson, M., Fossdal, R., Thorgeirsson, T. E., Thorsteinsdottir, U., Ruggeri, M., Tosato, S., Franke, B., Strengman, E., Kiemeney, L. A., Melle, I., Djurovic, S., Abramova, L., Kaleda, V., Sanjuan, J., de Frutos, R., Bramon, E., Vassos, E., Fraser, G., Ettinger, U., Picchioni, M., Walker,
N., Toulopoulou, T., Need, A. C., Ge, D., Yoon, J. L., Shianna, K. V., Freimer, N. B., Cantor, R. M., Murray, R., Kong, A., Golimbet, V., Carracedo, A., Arango, C., Costas, J., Jonsson, E. G., Terenius, L., Agartz, I., Petursson, H., Nothen, M. M., Rietschel, M., Matthews, P. M., Muglia, P., Peltonen, L., St Clair, D., Goldstein, D. B., Stefansson, K., and Collier, D. A. (2009). Common variants conferring risk of schizophrenia. Nature 460, 744-747.

Stefansson, H., Sarginson, J., Kong, A., Yates, P., Steinthorsdottir, V. Gudfinnsson, E., Gunnarsdottir, S., Walker, N., Petursson, H., Crombie, C., Ingason, A., Gulcher, J. R., Stefansson, K., and St Clair, D. (2003). Association of neuregulin 1 with schizophrenia confirmed in a scottish population. Am. J. Hum. Genet. 72, 83-87.

Stefansson, H., Sigurdsson, E., Steinthorsdottir, V., Bjornsdottir, S., Sigmundsson, T., Ghosh, S., Brynjolfsson, J., Gunnarsdottir, S., Ivarsson, O., Chou, T. T., Hjaltason, O., Birgisdottir, B., Jonsson, H., Gudnadottir, V. G., Gudmundsdottir, E., Bjornsson, A., Ingvarsson, B., Ingason, A., Sigfusson, S., Hardardottir, H., Harvey, R. P., Lai, D., Zhou, M., Brunner, D., Mutel, V., Gonzalo, A., Lemke, G., Sainz, J., Johannesson, G., Andresson, T., Gudbjartsson, D., Manolescu, A., Frigge, M. L., Gurney, M. E., Kong, A., Gulcher, J. R., Petursson, H., and Stefansson, K. (2002). Neuregulin 1 and susceptibility to schizophrenia. Am. J. Hum. Genet. 71, 877-892.

Stolp, H. B., Dziegielewska, K. M., Ek, C. J., Habgood, M. D., Lane, M. A., Potter, A. M., and Saunders, N. R. (2005). Breakdown of the bloodbrain barrier to proteins in white matter of the developing brain following systemic inflammation. Cell Tissue Res. 320, 369-378.

Stolp, H. B., Ek, C. J., Johansson, P. A., Dziegielewska, K. M., Bethge, N., Wheaton, B. J., Potter, A. M., and Saunders, N. R. (2009). Factors involved in inflammation-induced developmental white matter damage. Neurosci. Lett. 451, 232-236.

Stolp, H. B., Turnquist, C., Dziegielewska, K. M., Saunders, N. R., Anthony, D. C., and Molnar, Z. (2011). Reduced ventricular proliferation in the foetal cortex following maternal inflammation in the mouse. Brain.

Stubbs, D., Deproto, J., Nie, K., Englund, C., Mahmud, I., Hevner, R., and Molnar, Z. (2009). Neurovascular 
congruence during cerebral cortical development. Cereb. Cortex 19(Suppl. 1), i32-i41.

Sullivan, S. M., Bjorkman, S. T., Miller, S. M., Colditz, P. B., and Pow, D. V. (2010a). Morphological changes in white matter astrocytes in response to hypoxia/ischemia in the neonatal pig. Brain Res. 1319, 164-174.

Sullivan, S. M., Bjorkman, S. T., Miller, S. M., Colditz, P. B., and Pow, D. V. (2010b). Structural remodeling of gray matter astrocytes in the neonatal pig brain after hypoxia/ischemia. Glia 58, 181-194.

Suszkiw, J. B. (2004). Presynaptic disruption of transmitter release by lead. Neurotoxicology 25, 599-604.

Talos, D. M., Fishman, R. E., Park, H., Folkerth, R. D., Follett, P. L., Volpe, J. J., and Jensen, F. E. (2006). Developmental regulation of alpha-amino-3-hydroxy-5methyl-4-isoxazole-propionic acid receptor subunit expression in forebrain and relationship to regional susceptibility to hypoxic/ischemic injury. I. Rodent cerebral white matter and cortex. J. Comp. Neurol. 497, 42-60.

Tarabykin, V., Stoykova, A., Usman, N., and Gruss, P. (2001). Cortical upper layer neurons derive from the subventricular zone as indicated by Svetl gene expression. Development 128, 1983-1993.

Thomas, T., Southwell, B. R., Schreiber, G., and Jaworowski, A. (1990). Plasma protein synthesis and secretion in the visceral yolk sac of the fetal rat: gene expression, protein synthesis and secretion. Placenta 11, 413-430.

Toga, A. W., Thompson, P. M., and Sowell, E. R. (2006). Mapping brain maturation. Trends Neurosci. 29, 148-159.

Trejo, J. L., Machin, C., Arahuetes, R. M., and Rua, C. (1995). Influence of maternal adrenalectomy and glucocorticoid administration on the development of rat cerebral cortex. Anat. Embryol. 192, 89-99. van Os, J., Kenis, G., and Rutten, B. P. F. (2010). The environment and schizophrenia. Nature 468, 203-212.

Van Winkel, R., Esquivel, G., Kenis, G., Wichers, M., Collip, D., Peerbooms, O., Rutten, B., Myin-Germeys, I., and Van Os, J. (2010). Review: genome-wide findings in schizophrenia and the role of geneenvironment interplay. CNS $\mathrm{Neu}$ rosci. Ther. 16, e185-e192.

Vasudevan, A., Long, J. E., Crandall, J. E., Rubenstein, J. L., and Bhide, P. G. (2008). Compartmentspecific transcription factors orchestrate angiogenesis gradients in the embryonic brain. Nat. Neurosci. 11, 429-439.

Verney, C., Monier, A., Fallet-Bianco, C., and Gressens, P. (2010). Early microglial colonization of the human forebrain and possible involvement in periventricular white-matter injury of preterm infants. J. Anat. 217, 436-448.

Virgintino, D., Maiorano, E., Errede, M., Vimercati, A., Greco, P., Selvaggi, L., Roncali, L., and Bertossi, M. (1998). Astroglia-microvessel relationship in the developing human telencephalon. Int. J. Dev. Biol. 42, 1165-1168.

Volk, D. W., Austin, M. C., Pierri, J. N., Sampson, A. R., and Lewis, D. A. (2000). Decreased glutamic acid decarboxylase67 messenger rna expression in a subset of prefrontal cortical gamma-aminobutyric acid neurons in subjects with schizophrenia. Arch. Gen. Psychiatry 57, 237-245.

Volpe, J. J. (2009). The encephalopathy of prematurity-brain injury and impaired brain development inextricably intertwined. Semin Pediatr. Neurol. 16, 167-178.

Whitelaw, A., and Thoresen, M. (2000). Antenatal steroids and the developing brain. Arch. Dis. Childhood. 83, F154-F157.

Wichterle, H., Garcia-Verdugo, J. M., Herrera, D. G., and Alvarez-
Buylla, A. (1999). Young neurons from medial ganglionic eminence disperse in adult and embryonic brain. Nat. Neurosci. 2, 461-466.

Williams, B. P., and Price, J. (1995). Evidence for multiple precursor cell types in the embryonic rat cerebral cortex. Neuron 14, 1181-1188.

Williamson, L. L., Sholar, P. W., Mistry, R. S., Smith, S. H., and Bilbo, S. D. (2011). Microglia and memory: modulation by early-life infection. $J$. Neurosci. 31, 15511-15521.

Wilson, S. L., Wilson, J. P., Wang, C., Wang, B., and McConnell, S. K. (2011). Primary cilia and Gli3 activity regulate cerebral cortical size. Dev. Neurobiol.

Wonders, C. P., and Anderson, S. A. (2006). The origin and specification of cortical interneurons. Nat. Rev. Neurosci. 7, 687-696.

Wu, S. X., Goebbels, S., Nakamura, K. Kometani, K., Minato, N., Kaneko, T., Nave, K. A., and Tamamaki, N. (2005). Pyramidal neurons of upper cortical layers generated by NEXpositive progenitor cells in the subventricular zone. Proc. Natl. Acad. Sci. U.S.A. 102, 17172-17177.

$\mathrm{Xu}, \mathrm{M}$, and He, L. (2010). Convergent evidence shows a positive association of interleukin-1 gene complex locus with susceptibility to schizophrenia in the caucasian population. Schizophr. Res. 120 131-142.

Yoon, B. H., Romero, R., Park, J. S., Kim C. J., Kim, S. H., Choi, J. H., and Han, T. R. (2000). Fetal exposure to an intra-amniotic inflammation and the development of cerebral palsy at the age of three years. Am. J. Obstet. Gynecol. 182, 675-681.

Zammit, S., Odd, D., Horwood, J., Thompson, A., Thomas, K., Menezes, P., Gunnell, D., Hollis, C., Wolke, D., Lewis, G., and Harrison, G. (2009). Investigating whether adverse prenatal and perinatal events are associated with nonclinical psychotic symptoms at age
12 years in the ALSPAC birth cohort. Psychol. Med. 39, 1457-1467.

Zhao, J., Kim, K. D., Yang, X., Auh, S., Fu, Y. X., and Tang, H. (2008). Hyper innate responses in neonates lead to increased morbidity and mortality after infection. Proc. Natl. Acad. Sci. U.S.A. 105, 7528.

Zhong, J., Kim, H. T., Lyu, J., Yoshikawa, K., Nakafuku, M., and Lu, W. (2011). The Wnt receptor Ryk controls specification of GABAergic neurons versus oligodendrocytes during telencephalon development. Development 138, 409-419.

Zhong, W., and Chia, W. (2008). Neurogenesis and asymmetric cell division. Curr. Opin. Neurobiol. 18, 4-11.

Zoeller, R. T., and Rovet, J. (2004). Timing of thyroid hormone action in the developing brain: clinical observations and experimental findings. $J$. Neuroendocrinol. 16, 809-818.

Conflict of Interest Statement: The authors declare that the research was conducted in the absence of any commercial or financial relationships that could be construed as a potential conflict of interest.

Received: 01 December 2011; accepted: 01 May 2012; published online: 12 June 2012.

Citation: Stolp H, Neuhaus A, Sundramoorthi $R$ and Molnár Z (2012) The long and the short of it: gene and environment interactions during early cortical development and consequences for longterm neurological disease. Front. Psychiatry 3:50. doi: 10.3389/fpsyt.2012.00050 This article was submitted to Frontiers in Molecular Psychiatry, a specialty of Frontiers in Psychiatry.

Copyright () 2012 Stolp, Neuhaus, Sundramoorthi and Molnár. This is an openaccess article distributed under the terms of the Creative Commons Attribution Non Commercial License, which permits non-commercial use, distribution, and reproduction in other forums, provided the original authors and source are credited. 